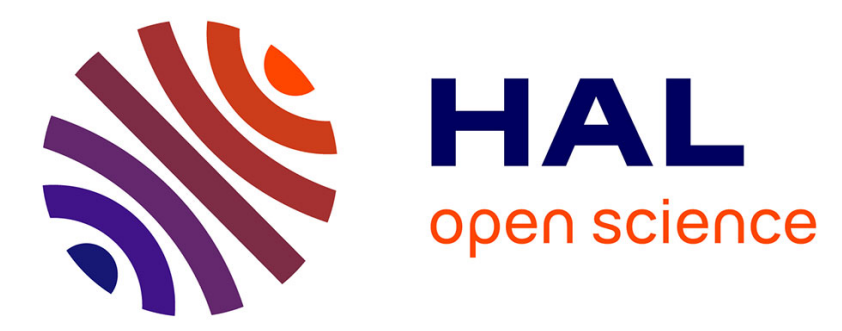

\title{
Hydrothermal synthesis and characterization of dioctahedral smectites: A montmorillonites series
}

Sébastien Lantenois, Rémi Champallier, Jean-Michel Bény, Fabrice Muller

\section{To cite this version:}

Sébastien Lantenois, Rémi Champallier, Jean-Michel Bény, Fabrice Muller. Hydrothermal synthesis and characterization of dioctahedral smectites: A montmorillonites series. Applied Clay Science, 2008, 38 (3-4), pp.165-178. 10.1016/j.clay.2007.03.005 . insu-00160450

\section{HAL Id: insu-00160450}

https://hal-insu.archives-ouvertes.fr/insu-00160450

Submitted on 6 Jul 2007

HAL is a multi-disciplinary open access archive for the deposit and dissemination of scientific research documents, whether they are published or not. The documents may come from teaching and research institutions in France or abroad, or from public or private research centers.
L'archive ouverte pluridisciplinaire HAL, est destinée au dépôt et à la diffusion de documents scientifiques de niveau recherche, publiés ou non, émanant des établissements d'enseignement et de recherche français ou étrangers, des laboratoires publics ou privés. 


\title{
Hydrothermal synthesis and characterization of dioctahedral smectites: A montmorillonites series
}

\author{
S. Lantenois ${ }^{\text {a, b }}$, R. Champallier ${ }^{\text {a }}$, J.-M. Bény ${ }^{\text {a }}$ and F. Muller ${ }^{a}$ \\ ${ }^{a}$ Institut des Sciences de la Terre d'Orléans (ISTO), CNRS-Université d'Orléans, 1A rue de la \\ Férollerie, 45071 Orléans Cedex 2, France \\ bAIME (Agrégats, Interfaces et Matériaux pour l'Energie), Institut Charles Gerhardt, CNRS \\ UMR 5253, UM2, ENSCM, CC 015, Place Eugène Bataillon, 34095 Montpellier Cedex 5, \\ France
}

\begin{abstract}
The aim of this study is to synthesize and finely characterize montmorillonite samples, dioctahedral smectites without tetrahedral charges (structural formulae $\left.\mathrm{Na}_{x}\left(\mathrm{Al}_{(2-x)} \mathrm{Mg}_{x}\right) \mathrm{Si}_{4} \mathrm{O}_{10}(\mathrm{OH})_{2}\right)$, to allow their use as reference samples in clay science. The montmorillonites synthesis under hydrothermal conditions at different pressures and with various layer charge deficit has been attempted. The temperature was fixed at $320{ }^{\circ} \mathrm{C}$, the pressure parameter values were $20 \mathrm{MPa}, 80 \mathrm{MPa}, 120 \mathrm{MPa}$ and $200 \mathrm{MPa}$. The $\mathrm{Mg}$ content varied from 0.25 to 0.60 per half unit cell. The reaction products have been characterized with multi-technique analyses (ICP-AES, EMP, CEC, XRD, FTIR, NMR and TGA).

Montmorillonite phase was only produced at 120 and $200 \mathrm{MPa}$.

At 20 and $80 \mathrm{MPa}$, the results suggest that a 0.33 and 0.16-tetrahedral charge deficit exist in the formed samples. Moreover, the octahedral occupancies are higher than two (2.15 and 2.07 at 20 and $80 \mathrm{MPa}$ respectively). In these experimental conditions, the synthetic smectites are mixtures between montmorillonite, beidellite and saponite.
\end{abstract}

At $120 \mathrm{MPa}$ and for a $\mathrm{Mg}$ content of 0.25 or higher than 0.33 , the synthetic products were also mixtures of smectites. Tetrahedral charge deficits of $0.11,0.11$ and 0.15 were found for $\mathrm{Mg}$ contents of $0.25,0.50$ and 0.60 respectively. The octahedral occupancy was also higher than 2.00 .

A montmorillonite phase with only octahedral charges and an octahedral occupancy near 2.00 was synthesized for a $\mathrm{Mg}$ content of 0.33 and at pressures equal to or higher than $120 \mathrm{MPa}$. This low charge reference smectite shows a very low amount of accessory minerals and an octahedral charge deficit only created by the presence of magnesium in the structure. This montmorillonite can be compared structurally to the most studied natural one: the montmorillonite SWy-2 from Wyoming.

Keywords: Hydrothermal synthesis; Dioctahedral smectites; Synthetic montmorillonite; Thermal analysis; Infrared spectroscopy; X-ray diffraction; ${ }^{27} \mathrm{Al} \mathrm{NMR} ;{ }^{29} \mathrm{Si}$ NMR 


\section{Introduction}

Smectites are one of the most common phyllosilicates family found in soils and sediments. Their specific characteristics, such as a high specific surface area, cation exchange capacities or hydration properties, give to this clay mineral family many industrial interests and a great variety of applications (nanocomposite science, ceramic manufacturing, cosmetics industry, waste confinement or soils decontamination). The natural smectite materials have numerous chemical and mineralogical compositions which can induced great changes in the properties such as charge deficit, cation exchange capacity or structural and microstructural characteristics. These properties should produce important behaviour variations in the industrial processes. However, some of these characteristics, such as the presence of accessory minerals may limit the potential use of smectites without a pretreatment. A possibility to avoid pretreatments is to use synthetic smectite.

Few studies realized in the last 40 years have been realized with the objective to determine stability fields of synthetic smectites. All these studies are summarized in a critical review published by Kloprogge et al. (1999). Some smectites are currently synthesized and used in clay science. For instance, synthetic trioctahedral smectites such as saponites (Suquet et al., 1977, Suquet et al., 1982 and Pelletier et al., 1999), hectorites (Carrado et al., 1997) or laponites (Qi et al., 1996) are often used as reference samples and sometimes industrially produced (see the Clay Minerals repository). However, whereas the dioctahedral smectites subfamily is predominant in soils and widely used in industry, these smectites are rarely synthesized and used in industrial developments or experimental researchs.

The stability field of the different dioctahedral smectites has been investigated for beidellite (Kloprogge et al., 1990 and Kloprogge et al., 1993), nontronite (Decarreau et al., 1987) and montmorillonite (Nakazawa et al., 1991, Yamada et al., 1991, Yamada et al., 1994a and Yamada et al., 1994b). For montmorillonite synthesis, Sand et al. (1953), Roy and Sand (1956) and Sand et al. (1957) have realized some experimental runs but the differentiation between montmorillonite and beidellite was not clearly established (Kloprogge et al., 1999). Moreover, a big part of the hydrothermal syntheses realized by these authors, have been performed without magnesium, which is necessary to obtain montmorillonite samples. Nevertheless, the temperature of synthesis of dioctahedral smectites seems to be limited between 250 and $450^{\circ} \mathrm{C}$. Harward and Brindley (1966) have synthesized montmorillonites at $300-350{ }^{\circ} \mathrm{C}$ and $100 \mathrm{MPa}$, but the reaction product, coming from these experiments, is composed of a mixture of montmorillonite, beidellite, saponite, paragonite, kaolinite and amorphous material. Levinson and Vian (1966) and Levinson and Day (1968) have synthesized a mixture between montmorillonite and calcite by reaction of dolomite, kaolinite, quartz and water at $300^{\circ} \mathrm{C}$. Yamada et al., 1994a and Yamada et al., 1994b have also obtained a mixture of minerals containing montmorillonite at high pressure and high temperature. Yamada et al. (1991) and Nakazawa et al. (1991) synthesized montmorillonites or montmorillonite/beidellite mixtures by hydration of $\mathrm{Na}-\mathrm{Mg}$-aluminosilicate glasses under a hydrothermal pressure of $100 \mathrm{Mpa}$ and with varying water/solid ratio. Only montmorillonite was obtained below $375^{\circ} \mathrm{C}$ with Mg-rich glass phases but only XRD patterns were realized in order to characterize these samples. All these studies highlighted the difficulties to synthesize only the montmorillonite phase. In addition, the lack of complete characterization of the formed products, limits the use of these materials (Kloprogge et al., 1999). 
The aim of this study is to synthesize and finely characterize dioctahedral smectite samples to permit their use as reference samples in clay science. In this study, Na-montmorillonite samples (theoretical formula $\mathrm{Na}_{x}\left(\mathrm{Al}_{(2-x)} \mathrm{Mg}_{x}\right) \mathrm{Si}_{4} \mathrm{O}_{10}(\mathrm{OH})_{2}$ ) are synthesized under different experimental conditions in order to obtain single-phase synthetic samples.

In the first part of this study, the synthesis pressure influence on the nature of reacted products is investigated; the layer charge deficit, corresponding to the $x$ suffix in the theoretical formula, is fixed at 0.33 for this part.

In the second part, the results obtained on samples synthesized with various layer charge deficits $(0,25<\times<0,6)$ are discussed.

Obtained samples are characterized by atomic emission spectroscopy (ICP-AES), electron microprobe, powder X-ray diffraction (XRD), fast Fourier transform infrared spectroscopy (FTIR), thermal gravimetric analyses (TGA), ${ }^{27} \mathrm{Al}$ and ${ }^{29} \mathrm{Si}$ MAS NMR and cationic exchange capacity (CEC) measurements.

\section{Experimental procedures}

\subsection{Starting materials}

The synthetic clay samples were crystallized from gels under hydrothermal conditions. The chemical composition of the gel phases was chosen to correspond to the ideal chemical composition of the desired smectite phase. The variation of the layer charge deficit from 0.25 to 0.60 was obtained by modification of the $\mathrm{Mg}$ content.

Gels were prepared following a method adapted from Hamilton and Henderson (1968) using: tetraethylorthosilicate (TEOS, Fluka) as the silicon source, $\mathrm{Mg}\left(\mathrm{NO}_{3}\right)_{2} \cdot 6 \mathrm{H}_{2} \mathrm{O}$ (Merck), $\mathrm{Al}\left(\mathrm{NO}_{3}\right)_{3} .9 \mathrm{H}_{2} \mathrm{O}$ (Merck), $\mathrm{HNO}_{3}$ (Aldrich), $\mathrm{Na}_{2} \mathrm{CO}_{3}$ (Merck), $\mathrm{NH}_{4} \mathrm{OH}$ (Aldrich) and ethanol (Aldrich) as reagents with a 99\% minimum grade purity. After dissolution of Al- and Mgnitrates and of $\mathrm{Na}_{2} \mathrm{CO}_{3}\left(19.68 \mathrm{~g}, 2,71 \mathrm{~g}\right.$ and $0.56 \mathrm{~g}$ respectively for the $\mathrm{GM}_{0.33}$ gel phase Table 1) in $45 \mathrm{ml}$ of nitric acid $0.45 \mathrm{M}$, TEOS (26.26 g, for the $\mathrm{GM}_{0.33}$ gel phase) and ethanol $(30 \mathrm{ml})$ were added. A precipitate was obtained by neutralizing the resulting solution at $\mathrm{pH}$ $\sim 6$ by addition of $\mathrm{NH}_{4} \mathrm{OH}(0.2 \mathrm{M})$. This precipitate was dried at $80^{\circ} \mathrm{C}$ for $24 \mathrm{~h}$, ground in an agate mortar and heated $30 \mathrm{~min}$ up to $400{ }^{\circ} \mathrm{C}$ to remove the nitrates and to obtain $\mathrm{Al}, \mathrm{Mg}, \mathrm{Si}$ and $\mathrm{Na}$ oxide gels.

The final gel phases are amorphous phases (controlled by XRD). Their chemical compositions were measured by ICP and are reported in Table 1.

\subsection{Hydrothermal syntheses}

Samples were synthesized in an internally heated pressure vessel. $0.1 \mathrm{~g}$ of gel and deionized water (weight ratio $1 / 2)$ were loaded in a gold tube $(0.7 \mathrm{ml}$ internal volume). The tube was then sealed and heated to $320^{\circ} \mathrm{C}$ under different argon pressures (between 20 and $200 \mathrm{MPa}$ ) during 15 days. Two sets of experiments were realized, one with $\mathrm{GM}_{0.33}$ starting gel at different pressures and the second one by using different gel phases with variable $\mathrm{Mg}$ content at a fixed pressure of $120 \mathrm{MPa}$. The different experimental conditions of the syntheses are reported in Table 2. Additional experiments were also performed during 10, 30 and 45 days 
on $\mathrm{SM}_{0.33}$ sample at $120 \mathrm{MPa}$ in order to study the smectite synthesis kinetics. After cooling of the vessels, the solid products were extracted from the reaction tubes, washed with distilled water, dried at $80{ }^{\circ} \mathrm{C}$ overnight and ground before structural and chemical characterizations.

\subsection{Characterizations}

The chemical compositions of the starting gel phases were checked by ICP-AES analysis using a JOBIN-YVON ULTIMA spectrometer. $100 \mathrm{mg}$ of a gel was dissolved by acid attack after alkaline fusion and the $\mathrm{Si}, \mathrm{Al}, \mathrm{Mg}$ and $\mathrm{Na}$ concentrations were measured.

The chemical compositions of the synthesized products were performed using a CAMECA SX50 electron microprobe (EMPA) operating at $15 \mathrm{kV}$ accelerating voltage. The analyzed samples were previously washed in ethanol and then dialyzed in deionized water for 1 week. After dialyze, the $<2 \mu \mathrm{m}$ size fraction of samples, which mainly corresponds to the clay fraction, was extracted, dried and finely ground in an agate mortar. Knowing that the best microprobe analyzes are realized on flat surfaces, the sample powder was pressed in an evacuable die to prepare a pellet. A part of this pellet was fixed on a glass slide and then silver metallized before analysis.

Powder XRD patterns were recorded in transmission geometry using CoK $\alpha$ radiation $(35 \mathrm{~mA}$, $35 \mathrm{kV}$ ). The use of an INEL CPS 120 curved position sensitive detector allows the diffracted intensity to be recorded simultaneously over a $4-50^{\circ} 2 \theta$ range with a $0.03^{\circ}$ step size. The nonlinearity of the detector response was corrected (Roux and Volfinger, 1996). A $0.5 \mathrm{~mm}$ diameter Lindemann glass tube was used to hold the sample powder. The XRD patterns were recorded using raw samples dried at $80{ }^{\circ} \mathrm{C}$ and grounded. In order to make the distinction between smectites with predominantly octahedral or tetrahedral charges, an expandability test adapted from the Greene-Kelly (GK) test, (Greene-Kelly, 1953 and Lim and Jackson, 1986) based on the Hofmann-Klemen effect (Hofmann and Klemen, 1950) has been performed on some samples. For this test, the montmorillonite samples were prepared by washing the reaction product three times with aqueous $\mathrm{LiCl}(1 \mathrm{M})$ and once with ethanol. The Li-saturated samples were dialyzed during 3 days, then dried at $80^{\circ} \mathrm{C}$ and ground. Powders were placed in ceramic crucibles, heated overnight at $350{ }^{\circ} \mathrm{C}$ and then put into a water saturated atmosphere during 2 days to allow rehydration of the samples before XRD analysis. Finally, the XRD patterns show peaks which correspond to a $9.5 \AA$ (001) basal spacing for collapsed octahedral charge smectites and to a $12.5 \AA$ (001) basal spacing for tetrahedrally charged smectites.

Infrared spectra (IR) were recorded using a NICOLET Magna-IR 760 Fourier transform spectrometer. To avoid the $\mathrm{K}^{+}-\mathrm{Na}^{+}$exchange within sample during analysis and to remove the contribution of the water absorbed by the $\mathrm{KBr}$ pellet in the spectral range of $\mathrm{O}-\mathrm{H}$ stretching band, a NICOLET Nic-Plan microscope was used. The spectrometer and the microscope were purged with dry air to remove most of atmospheric $\mathrm{H}_{2} \mathrm{O}$ and $\mathrm{CO}_{2}$. The powder was spread over the $\mathrm{NaCl}$ window of the microscope stage. The analysed sample area was a $100 \mu \mathrm{m}$ diameter circle chosen under the microscope 15X Cassegrainian objective. The operating conditions were 200 scans, $2 \mathrm{~cm}^{-1}$ resolution with no ambient $\mathrm{CO}_{2}-\mathrm{H}_{2} \mathrm{O}$ corrections. The studied wavenumber range was $650 \mathrm{~cm}^{-1}-4000 \mathrm{~cm}^{-1}$ according to the spectrometer beamsplitter, the sample holder type ( $\mathrm{NaCl}$ here) and the microscope detector (NICOLET MCT-A).

The cation exchange capacity (CEC) was measured using the copper complex method (Gaboriau, 1991) for which $600 \mathrm{mg}$ of the sample were suspended for $12 \mathrm{~h}$ in $25 \mathrm{ml}$ of a 
$0.01 \mathrm{M}$ ethylene di-amine copper complex $\left(\mathrm{Cu}(\mathrm{EDA})_{2} \mathrm{Cl}_{2}\right)$ solution. After centrifugation, the solution $\mathrm{Cu}$ concentration was measured using a 905-GBC atomic absorption spectrophotometer from GBC Scientific Equipment.

Transmission Electron Microscopy (TEM) observations were performed using a JEOL 2000 FX microscope operating at $200 \mathrm{kV}$. Samples were prepared as a suspension in ethanol, from which a drop was dried on copper grids covered with a carbon film.

The ${ }^{27} \mathrm{Al}$ and ${ }^{29} \mathrm{Si}$ MAS NMR spectra of the solid samples were obtained, at room temperature, using an Avance 300 Brucker spectrometer. The relevant parameters of the solid state NMR for the two different nuclei are listed in Table 3. Decomposition of the NMR ${ }^{27} \mathrm{Al}$ and ${ }^{29} \mathrm{Si}$ spectra was performed with Peak-Fit (v4.05) software using Gaussian curves for ${ }^{29} \mathrm{Si}$ spectra and asymmetric Gaussian curves for ${ }^{27} \mathrm{Al}$ spectra.

The Thermal Gravimetric Analyses (TGA) were recorded with a SETARAM TGA 92 microanalyser, with a heating rate of $10 \mathrm{~K} / \mathrm{min}$ under $\mathrm{N}_{2}$ atmosphere. A 60 -mg sample was used for each measurement. The derivative of the TG curve (DTG) gives the weight loss by degree, which was assigned to hydration water between 20 and $200{ }^{\circ} \mathrm{C}$ and to water evolved from hydroxyl groups between 500 and $750{ }^{\circ} \mathrm{C}$.

\subsection{Quantification of the relative proportion of synthesized smectite}

The synthesis yield was estimated by TGA measurement. The amount of $\mathrm{H}_{2} \mathrm{O}$ loss between 400 and $800{ }^{\circ} \mathrm{C}(\Delta \mathrm{m}$ in Fig. 1B) which corresponds to the dehydroxylation process was measured and compared to the amount of structural $\mathrm{OH}$ loss calculated for $100 \%$ of smectite synthesized. For example, in $\mathrm{SM}_{0.33}$ sample, $100 \%$ of smectite synthesized corresponds to a $\mathrm{H}_{2} \mathrm{O}$ mass loss of $4.95 \%$ ( $18 \mathrm{~g} / \mathrm{mol}$ for a dry smectite with a molar mass of $364 \mathrm{~g} / \mathrm{mol}$, calculated using the chemical composition of $\mathrm{GM}_{0.33}$ in Table 4). Relative proportions of synthesized smectite are presented in Table 4 . They are estimated from the ratio between the percentage of mass loss measured by TGA $\left(3,71 \%, 3,96 \%, 4,31 \%\right.$ and $4,26 \%$ for $\mathrm{SM}_{0.33}-200$, 800,1200 and 2000 respectively) and the one calculated for $100 \%$ of smectite synthesized.

In this quantification method, the potential mass loss of the residual amorphous phase was supposed to be null between 400 and $800{ }^{\circ} \mathrm{C}$ (Fig. 1A). The structural OH loss of neo-formed kaolinite phase, formed in negligible amount (see below), was also not considered but the absolute precision on the proportion of smectite formed was estimated to be $\pm 5 \%$.

\section{Results}

\subsection{Pressure evolution}

The experimental conditions used for the samples $\left(\mathrm{SM}_{0.33}-200, \mathrm{SM}_{0.33}-800, \mathrm{SM}_{0.33}-1200\right.$ and $\mathrm{SM}_{0.33}-2000$ ) starting with the $\mathrm{GM}_{0.33}$ gel phase (chemical composition in Table 1 and XRD patterns Fig. 2a) at four different pressures (20, 80, 120 and $200 \mathrm{MPa})$ are summarized in Table 2.

Smectite mineral is the predominant crystalline phase in all the reacted samples. It was clearly identified with $(00 \ell)$ reflections at $8.32^{\circ}(12.5 \AA), 17.08^{\circ}(6.8 \AA), 33.85^{\circ}(3.12 \AA)$ and (02.11), (20.13) bands at $23.2^{\circ}(4.45 \AA), 41.53^{\circ}(2.55 \AA)$ respectively (XRD patterns, Fig. 2). 
The presence of a small amount of kaolinite was also observed at 20 and $80 \mathrm{MPa}$ (Fig. 2b and c). A difference between the $\mathrm{SM}_{0.33}-200$ sample and the others appears after the GK test (Fig. $2 b$ ). For the three samples $\mathrm{SM}_{0.33}-800, \mathrm{SM}_{0.33}-1200$ and $\mathrm{SM}_{0.33}-2000$, the (001) reflection peak shifts from $\cong 12,5 \AA$ to $\cong 9.5 \AA\left(10.87^{\circ}\right.$, Fig. $2 \mathrm{c}, \mathrm{d}$ and e), while for the $\mathrm{SM}_{0.33}-200$ sample this reflection peak shifts near $10.8 \AA\left(10.24^{\circ}\right.$, Fig. $\left.2 \mathrm{~b}\right)$ and broadens.

On the infrared spectra, a vibration band was observed for all samples between 3648 and $3660 \mathrm{~cm}^{-1}$ in the $\mathrm{OH}$ bond stretching range (Fig. 3Ab, Ac, Ae and Af). This band was not present in the starting gel phase spectrum (Fig. 3Aa) and corresponds to the smectite structural $\mathrm{OH}$ bonds vibration band. The band at $3700 \mathrm{~cm}^{-1}$ indicates that a small amount of kaolinite is present in all the samples. In the reacted products, some characteristic smectite bands appear in the $\mathrm{OH}$ bending range between 800 and $950 \mathrm{~cm}^{-1}$ (Fig. 3Bb, Bc, Be and Bf). Three bands at 805,885 and $918 \mathrm{~cm}^{-1}$ were identified in the four samples $\left(\mathrm{SM}_{0.33}-200\right.$, $\left.\mathrm{SM}_{0.33}-800, \mathrm{SM}_{0.33}-1200, \mathrm{SM}_{0.33}-2000\right)$. A band at $850 \mathrm{~cm}^{-1}$ is observed in $\mathrm{SM}_{0.33}-800$, $\mathrm{SM}_{0.33}-1200$ and $\mathrm{SM}_{0.33}-2000$ samples and at $830 \mathrm{~cm}^{-1}$ in $\mathrm{SM}_{0.33}-200$ and $\mathrm{SM}_{0.33}-800$ samples. The interpretation of all these vibration bands will be discussed below.

Differences between the $\mathrm{SM}_{0.33}-200$ and $\mathrm{SM}_{0.33}-800$ and the other two $\left(\mathrm{SM}_{0.33}-1200, \mathrm{SM}_{0.33^{-}}\right.$ 2000) were observed in chemical analyses (Table 4). A silicon content deficit was observed and partially balanced by the presence of aluminum in the tetrahedral sheet. The layer charge deficit was mainly localized in the tetrahedral sheet for $\mathrm{SM}_{0.33}-200$, shared out between octahedral and tetrahedral sheets for $\mathrm{SM}_{0.33}-800$ and predominantly found in the octahedral sheet for $\mathrm{SM}_{0.33}-1200$ and $\mathrm{SM}_{0.33}-2000$ samples. The chemical composition of $\mathrm{SM}_{0.33}-1200$ sample was equivalent to those of $\mathrm{SM}_{0.33}-2000$ sample and closely related to the starting gel phase chemical composition (structural formula in Table 4). The octahedral occupancy equals 2.02 for the two samples and the octahedral charge is 5.70e for $\mathrm{SM}_{0.33}-1200$ and 5,71e for $\mathrm{SM}_{0.33}-2000$. On the contrary, the octahedral occupancy values are 2.15 and 2.07 for $\mathrm{SM}_{0.33^{-}}$ 200 and $\mathrm{SM}_{0.33}-800$ samples respectively. These results are probably correlated with a very high octahedral charge value (5.97e and 5,83e for $\mathrm{SM}_{0.33}-200$ and $\mathrm{SM}_{0.33}-800$ respectively).

The CEC starting values were approximately the same for the four samples but after GK test, these CEC values became different from a sample to another. The CEC decrease was high for $\mathrm{SM}_{0.33}-1200$ and $\mathrm{SM}_{0.33}-2000$ (109 to 8 and 112 to $10 \mathrm{meq} / 100 \mathrm{~g}$ respectively), while it was low for $\mathrm{SM}_{0.33}-800$ (104 to $42 \mathrm{meq} / 100 \mathrm{~g}$ ) and even lower for $\mathrm{SM}_{0.33}-200$ sample (111 to $81 \mathrm{meq} / 100 \mathrm{~g})$. These results confirm some differences of charge deficit distribution between the octahedral and the tetrahedral sheets in the synthetic smectite samples.

\subsection{Evolution of the layer charge deficit}

A second experimental run was realized at $120 \mathrm{MPa}$ with gel phases containing increasing amount of magnesium (chemical compositions in Table 1) in order to modify the smectite layer charge. The experimental conditions used for the four samples $\left(\mathrm{SM}_{0.25}-1200, \mathrm{SM}_{0.33^{-}}\right.$ $1200, \mathrm{SM}_{0.50}-1200$ and $\left.\mathrm{SM}_{0.60}-1200\right)$ were summarized in Table 2.

For the four samples, smectite was the predominant crystalline phase. The X-ray patterns presented in Fig. 4 show that the smectite phase was clearly identified with $(00 \ell)$ reflection peaks at 12.5, 6.8 and $3.12 \AA$ and with (02.11) and (20.13) bands at $4.45 \AA$ and $2.55 \AA$ respectively (Fig. 4). A difference was just observed in the (06.33) band with the presence of a shoulder near $1.51 \AA$ in $\mathrm{SM}_{0.50^{-}} 1200$ and $\mathrm{SM}_{0.60^{-}}-1200$ samples. This shoulder, which is 
characteristic of the presence of trioctahedral domains in the octahedral sheets of smectites (see below), is stronger in $\mathrm{SM}_{0.60}-1200$.

The infrared spectroscopy spectra show a vibration band corresponding to the smectite structural $\mathrm{OH}$ stretching band between 3648 and $3650 \mathrm{~cm}^{-1}$ (Fig. 5A). A band at $3700 \mathrm{~cm}^{-1}$, corresponding to the kaolinite phase, was also observed. Some differences between samples spectra were observed in the $\mathrm{OH}$ bending region. If the bands at $805,850,885$ and $918 \mathrm{~cm}^{-1}$ were always observed, another band at $830 \mathrm{~cm}^{-1}$ was identified in the $\mathrm{SM}_{0.50}-1200$ and $\mathrm{SM}_{0.60}-1200$ samples (Fig. 5B). According to the discussion section, no assignment is given to this band.

Fig. 6 shows the derivative of the TGA curves. The mass loss between 550 and $750{ }^{\circ} \mathrm{C}$ corresponding to structural $\mathrm{OH}$ loss was maximum at $685^{\circ} \mathrm{C}$ for $\mathrm{SM}_{0.25}-1200$ and $\mathrm{SM}_{0.33^{-}}$ 1200 samples (Fig. 6a and b). This maximum shifted to 670 and $662^{\circ} \mathrm{C}$ for $\mathrm{SM}_{0.50}-1200$ and $\mathrm{SM}_{0.60}-1200$ samples respectively (Fig. $6 \mathrm{c}$ and d). Moreover, the presence of a second dehydroxylation maximum near $620{ }^{\circ} \mathrm{C}$ was observed in $\mathrm{SM}_{0.60}-1200$ samples.

Some differences between the $\mathrm{SM}_{0.25}-1200, \mathrm{SM}_{0.33}-1200$ samples and the others were also observed in the chemical analyses results (Table 4). For $\mathrm{SM}_{0.50^{-}}-1200$ and $\mathrm{SM}_{0.60^{-}}-1200$ samples, the octahedral cation occupancy values are higher than 2.00 (2.10 and 2.12 respectively) and the chemical formulae of the starting gels, calculated using the ICP-AES measured chemical composition, and those of the reaction products, calculated from the EMPA measured chemical composition, show significant discrepancies (see for example the tetrahedral aluminium or the octahedral magnesium contents).

\subsection{Comparison between $\mathrm{SM}_{0.33}-1200(x=0,33)$ and $\mathrm{SM}_{0.25}-1200(x<0,33)$}

The chemical composition of the $\mathrm{SM}_{0.33}-1200$ sample was closely related to the starting gel phase chemical composition (structural formulae Table 4) though the one calculated for $\mathrm{SM}_{0.25}-1200$ sample showed some differences. In this last sample, a tetrahedral charge deficit was observed and equal to 0.11 ; it's CEC value decrease from $91 \mathrm{meq} / 100 \mathrm{~g}$ to $22 \mathrm{meq} / 100 \mathrm{~g}$ after GK test, confirms this result.

\subsection{Comparison between $\mathrm{SM}_{0.33^{-1200}}(x=0.33)$ and $\mathrm{SM}_{0.50^{-1200}}, \mathrm{SM}_{0.60^{-}}$ $1200(x>0.33)$}

A comparison between the charge values of $\mathrm{SM}_{0.33}-1200$ sample and the other two samples $\mathrm{SM}_{0.50^{-}}-1200$ and $\mathrm{SM}_{0.60^{-}} 1200$, shows that the charge deficit came from the octahedral layer chemical composition for $\mathrm{SM}_{0.33}-1200$ sample though it was shared out between the octahedral and tetrahedral layers for the other two samples (Table 4). Similar conclusions were also drawn from the CEC measurement results. After GK test, the CEC value, which was $8 \mathrm{meq} / 100 \mathrm{~g}$ for $\mathrm{SM}_{0.33}-1200$ sample, increased up to 25 and $39 \mathrm{meq} / 100 \mathrm{~g}$ for $\mathrm{SM}_{0.50^{-}}$ 1200 and $\mathrm{SM}_{0.60}-1200$ samples respectively.

\subsection{Presence of residual gel phases}

Amorphous gel phase (Fig. 7A) used for the synthesis was always observed by TEM in $\mathrm{SM}_{0.33}-1200$ samples even after 15 days run duration (Fig. 7B) because of a not complete crystallization. In order to obtain samples with a lesser residual gel phase content, two 
experiments were realized, the increase of the run duration and the elimination of the amorphous phase by selection of the $<2 \mu \mathrm{m}$ size fine fraction corresponding classically to the clay fraction. In the TEM observations of $\mathrm{SM}_{0.33}-1200$ samples after 30 days and $\mathrm{SM}_{0.33}-1200$ $<2 \mu \mathrm{m}$ size fraction (Fig. 7C and D respectively), the presence of residual amorphous phase is not clearly identified.

An estimate of the relative proportion of synthesized smectite as a function of duration was obtained from TGA measurements. Results of this quantification were plotted for $\mathrm{SM}_{0.33}-1200$ sample on Fig. 8. The crystallization of montmorillonite proceeds rather rapidly. After only 10 days, $\cong 80 \%$ of montmorillonite was produced and a maximum of $95 \%$ was reached after 30 days. Longer run duration does not significantly improve the montmorillonite yield in these experimental conditions.

The estimate of the formed smectite weight obtained after 15 days are reported in Table 4. The elimination of an important part of the residual amorphous phase (between 70 and $90 \%$, determinated by TGA, data not shown) was realized by selection of the fine clay fraction (size of particles $<2 \mu \mathrm{m}$ ). These purified samples were only used in chemical analysis to obtain structural formulae that are more realistic.

\section{Discussion}

The hydrothermal synthesis products presented in this paper were predominantly smectite phases, associated with minor accessory phases (starting amorphous phase or kaolinite) which can be considered as impurities. The structural characteristics of the synthetic smectite phases were more or less different from the theoretical formula of the wished montmorillonite: $\mathrm{Na}_{x}\left(\mathrm{Al}_{(2-x)} \mathrm{Mg}_{x}\right) \mathrm{Si}_{4} \mathrm{O}_{10}(\mathrm{OH})_{2}$. In the following discussion, the influence of the pressure and gel composition will be discussed to determine the experimental conditions, which optimize the synthetic montmorillonite production.

\subsection{Influence of the pressure factor}

The stability field of synthetic montmorillonites was clearly fixed for temperatures between 220 and $450^{\circ} \mathrm{C}$ (Roy and Sand, 1956, Harward and Brindley, 1966, Nakazawa et al., 1991, Yamada et al., 1991, Reinholdt et al., 2001 and Reinholdt et al., 2005). In this literature, the pressure parameter was not studied in detail. It is often fixed at $100 \mathrm{MPa}$ for syntheses realized in an alkali to neutral medium (Harward and Brindley, 1966, Nakazawa et al., 1991 and Yamada et al., 1991) and lower than $10 \mathrm{MPa}$ for those realized in a slightly acidic and fluoride medium (Reinholdt et al., 2001 and Reinholdt et al., 2005). In the experimental conditions fixed in this study, synthesized smectites type depends on the pressure parameter.

At $20 \mathrm{MPa}$, the smectite $\mathrm{SM}_{0.33}-200$ was predominantly tetrahedrally substituted (Table 4). The presence of magnesium in the octahedral sheet was coupled with an octahedral occupancy higher than 2.00 , which can be associated with a di-trioctahedral smectite production (mixture between saponite and beidellite). This result was confirmed on the XRD pattern by a rather large (001) reflection near $10.8 \AA$ after GK test (Fig. 2b). The CEC decrease, after the GK test (from $111 \mathrm{meq} / 100 \mathrm{~g}$ to $81 \mathrm{meq} / 100 \mathrm{~g}$ ) also shows that this product is not a high purity montmorillonite, for which the CEC value equals approximately zero after Hofmann-Klemen effect (1950). The differentiation between montmorillonite, beidellite and saponite was difficult in the $\mathrm{OH}$ bonds stretching zone of the infrared spectra. However, some differences could be observed in the (cation, cation)- $\mathrm{OH}$ bending zone (Fig. 
$3 \mathrm{Bb})$. In dioctahedral smectites, two bands are classically associated with ( $\mathrm{Al}, \mathrm{Al})-\mathrm{OH}$ and (A1, $\mathrm{Mg})-\mathrm{OH}$ bending vibrations $\left(915 \mathrm{~cm}^{-1}\right.$ and $845 \mathrm{~cm}^{-1}$ respectively, Farmer, 1974 , Madejova et al., 2000, Madejova, 2003 and Gates, 2004). In your case, only one band at $918 \mathrm{~cm}^{-1}$ was observed. The absence of dioctahedral (Al, $\left.\mathrm{Mg}\right)-\mathrm{OH}$ band near $850 \mathrm{~cm}^{-1}$ can be associated with a di-trioctahedral sample. This di-trioctahedral sample can undiscernibly correspond to two segregated smectite phases or to a mixture between trioctahedral and dioctahedral layers in the same smectite phase. The other bands observed in the $\mathrm{OH}$ bending zone were not easily assigned and were discussed below (see 4-4 paragraph).

$\mathrm{SM}_{0.33}-800$ sample was different from the $\mathrm{SM}_{0.33}-200$ one. On its XRD pattern, the (001) reflection shifted to $9.5 \AA$ after GK test (Fig. 2c) which was characteristic of the montmorillonite presence in the reacted product (Hofmann and Klemen, 1950). The (06.33) reflection band at $1.49 \AA$, characteristic of a dioctahedral structure, has a shoulder at $1.51 \AA$ (Fig. 9b). This band at $1.51 \AA$, also identified in the $\mathrm{SM}_{0.33}-200$ sample (Fig. 9a), was characteristic of the presence of a trioctahedral structure (Grauby et al., 1993). This information was in accordance with the infrared data and the CEC results: presence of an (A1, $\mathrm{Mg}$ ) $-\mathrm{OH}$ band at $850 \mathrm{~cm}^{-1}$ in the $\mathrm{OH}$ bending zone (Fig. 3Bc) and significant decrease of the CEC value after GK test (Table 4). The chemical composition (Table 4) shows that for this sample, the di-trioctahedral character (beidellite and saponite phases), indicated by an octahedral occupancy equal to 2.07 is less strong than for the $\mathrm{SM}_{0.33}-200$ sample (2.15). This result was confirmed by the CEC measurement. A part of the CEC before GK test, remains after GK test (See Table 4 with CEC values equal to 104 and 42 meq/100 g respectively before and after GK test; $42 / 104 \cong 40.4 \%$ ).

$\mathrm{SM}_{0.33}-1200$ sample was characteristic of a montmorillonite phase containing a very small amount of kaolinite. On the XRD pattern, the (001) reflection shifted to $9.5 \AA$ after GK test (Fig. 2d) and the (06.33) band was symmetric and localized at $1.49 \AA$ (Fig. 9c). Two bands, an $(\mathrm{Al}, \mathrm{Mg})-\mathrm{OH}$ band at $850 \mathrm{~cm}^{-1}$ and an $(\mathrm{Al}, \mathrm{Al})-\mathrm{OH}$ band at $918 \mathrm{~cm}^{-1}$, were identified in the infrared data of the (Cation, Cation)-OH bonds bending zone (Fig. 3Be). After lithium exchange and heating (GK test), a second maximum peak appeared at $3668 \mathrm{~cm}^{-1}$ (Fig. 3Ad) and was assigned to a (Al, Mg, Li)- $\mathrm{OH}$ stretching vibration (Calvet and Prost, 1971). The chemical formula corresponds to a montmorillonite with mainly octahedral charge deficit, very low tetrahedral charge deficit and an octahedral occupancy near 2.00 (Table 4). The CEC measurement strongly decreased after lithium exchange and heating according to the decrease observed in the same conditions for natural reference montmorillonites. For example, in SAz1 sample studied by Madejova et al. (2000), the CEC of the $200{ }^{\circ} \mathrm{C}$ heated sample reached $13 \%$ of the unheated sample CEC. In thermal analysis, the loss of interlayer $\mathrm{H}_{2} \mathrm{O}$ was observed at temperatures lower than $200{ }^{\circ} \mathrm{C}$ (Fig. 1B) but the maximum loss of water arising from the dehydroxylation process was observed at $685^{\circ} \mathrm{C}$ (Fig. 6b). These results are comparable to the structural water maximum loss of SWy-2 sample (lower charged reference montmorillonite) identified by Guggenheim and Koster van Groos (2001) at $684{ }^{\circ} \mathrm{C}$. All these results indicate that the synthesized product in $\mathrm{SM}_{0.33}-1200$ sample was a montmorillonite.

The results obtained for the $\mathrm{SM}_{0.33}-2000$ sample show a strong similarity with those of the $\mathrm{SM}_{0.33}-1200$ one (Table 4). For pressures equal to or higher than $120 \mathrm{MPa}$ and a temperature equal to $320^{\circ} \mathrm{C}$, we can assume that the synthesized products were montmorillonites. 


\subsection{Montmorillonites with different layer charge deficit}

The product obtained with $x=0.25\left(\mathrm{SM}_{0.25}-1200\right.$ sample) was a montmorillonite with tetrahedral substitutions. The increase of the tetrahedral layer charge deficit of this sample by comparison with the starting gel phase one (Table 4) induced a silicon rich residual amorphous phase and a lower yield of the synthesis compared to the experiment $\mathrm{SM}_{0.33}-1200$ (Table 4). This result shows the impossibility to synthesize high purity montmorillonite with a layer charge lower than 0.33 in these experimental conditions; $x=0.33$ seems to be the smallest layer charge deficit value accepted in a pure montmorillonite.

The products of the conducted experiments with a layer charge deficit higher than $x=0.33$ show some differences with those of $\mathrm{SM}_{0.33}-1200$ sample. The layer charge deficits of the synthesized smectite phases have increased for $\mathrm{SM}_{0.50}-1200$ and $\mathrm{SM}_{0.60}-1200$ samples with a larger amount of octahedral $\mathrm{Mg}$. But, as for $\mathrm{SM}_{0.25}-1200$ sample, aluminium is found in the tetrahedral sheet and contributes to the total layer charge deficit. The values of the octahedral site occupancy (2,10 and 2,12 for $\mathrm{SM}_{0.50^{-}} 1200$ and $\mathrm{SM}_{0.60}-1200$ respectively, Table 4) indicate the presence of di-trioctahedral domains in these samples which were also identified on the XRD patterns (band at $1.51 \AA$, Fig. 4c, d). These results show that the layer charge deficit can be increased; however, this deficit is not only localized in the octahedral sheet as in a pure montmorillonite but distributed between the octahedral and tetrahedral sheets.

A good purity montmorillonite (total deficit of charge in octahedral sheet) was obtained only for samples with a low charge deficit equivalent to 0.33 per half unit cell $\left(\mathrm{SM}_{0.33}-1200\right.$ sample).

\section{3. $\mathrm{SM}_{0.33}-1200$ sample: a low charge montmorillonite?}

In these experimental runs, a montmorillonite with a minor amount of associated mineral phases was only synthesized with a low charge $\left(\mathrm{SM}_{0.33}-1200\right.$ sample). The chemical formula showed a very small amount of tetrahedral charges. This result can be confirmed by ${ }^{27} \mathrm{Al}$ and

${ }^{29}$ Si MAS NMR analyses (Fig. 10 and Fig. 11). In the ${ }^{29} \mathrm{Si}$ MAS NMR spectrum of $\mathrm{SM}_{0.33^{-}}$ 1200 sample (Fig. 10b), a $\mathrm{Si}(0 \mathrm{Al})$ sharp band associated to a small $\mathrm{Si}(1 \mathrm{Al})$ one were observed at -94 and -89 ppm respectively. Silica residual amorphous phase can not be detected because of a very small signal detected for the initial amorphous phase (Fig. 10a). The amount of tetrahedrally coordinated $\mathrm{Al}$ in the clay framework of the $\mathrm{SM}_{0.33}-1200$ sample can be estimated between 1 and $2 \%$ (Table 5) of the tetrahedral sites. In the ${ }^{27}$ Al MAS NMR spectrum of $\mathrm{SM}_{0.33}-1200$ sample (Fig. 11b), one band characteristic of octahedral aluminium near 0 ppm was identified; it was associated with two other bands at 53 and $61 \mathrm{ppm}$ identified as aluminium tetrahedrally coordinated (Sanz and Serratosa, 1984 and Reinholdt et al., 2001). By comparison with the NMR spectrum of the starting amorphous phase (Fig. 11a), the band at $61 \mathrm{ppm}$ can be associated with Al(IV) always present in the residual amorphous phase and the band at $53 \mathrm{ppm}$ can be attributed to the presence of aluminium in the tetrahedral sheet of the synthetic smectite phase. Using this band attribution, the amount of Al tetrahedrally coordinated in the clay framework of the $\mathrm{SM}_{0.33}-1200$ sample can be estimated near $1 \%$ (Table 5) of the tetrahedral sites in accordance with the quantification realized by ${ }^{29} \mathrm{Si}$ MAS NMR and the chemical formula (Table 4).

The amount of residual amorphous phase is estimated between 10 and $15 \mathrm{wt} . \%$ and can be minimized but not totally avoided. Its minimum is estimated near $5 \mathrm{wt} . \%$ with a synthesis duration longer than 30 days (Fig. 8). 
During the increase of temperature, the stability field of kaolinite (Kloprogge et al., 1993) is crossed and a little amount of this mineral is synthesized. The proportion of synthesized kaolinite was very low because no characteristic reflections were identified on the XRD patterns. Infrared spectroscopy technique has a better sensitivity for the kaolinite detection and it is possible to detect 5\% weight ratio of kaolinite in smectite by the presence of a $3700 \mathrm{~cm}^{-1}$ band in the infrared spectrum (Joussein et al., 2001). In $\mathrm{SM}_{0.33}-1200$ sample, kaolinite impurity was estimated to be around $1 \mathrm{wt} \%$ (Fig. 3Ae).

\subsection{Limits of the characterization techniques}

Kloprogge et al. (1999) in their critical review, point out the limits of some studies in the synthetic clay domain due to a lack of complete characterization of the formed products. In this study, the use of multi-technique analyses permitted a fine characterization (microprobe analysis, CEC measurement, GK test, XRD, ATG, FTIR, ${ }^{27} \mathrm{Al}$ and ${ }^{29} \mathrm{Si}$ MAS NMR, TEM). Nevertheless, some characterization aspects are not very well clarified. The tetrahedral charges found in some synthesized samples $\left(\mathrm{SM}_{0.33}-200, \mathrm{SM}_{0.33}-800, \mathrm{SM}_{0.25}-1200, \mathrm{SM}_{050^{-}}\right.$ 1200 and $\mathrm{SM}_{0.60}-1200$ ) can be assigned to the presence of tetrahedral substitutions in montmorillonite or to the presence of a beidellite phase. The octahedral occupancies upper than two in four samples $\left(\mathrm{SM}_{0.33}-200, \mathrm{SM}_{0.33}-800, \mathrm{SM}_{0.50}-1200\right.$ and $\left.\mathrm{SM}_{0.60}-1200\right)$ can be associated with a trioctahedral phase such as saponite. These saponite and beidellite phases can be associated with the montmorillonite phase by interstratification or segregation. These two possible situations are of no consequences for the production of a pure montmorillonite but are to be considered in the study of the stability field of synthesized smectites.

\section{Conclusion}

Synthetic montmorillonites are very interesting materials both for scientific research and industrial applications because they are reproducible and homogeneous; they are then useful for systematic studies, contrary to the natural montmorillonite samples. Indeed, by comparison with the most studied low charge reference natural montmorillonite (SWy-2), characterized in the Baseline Studies of the Clay Minerals Society Source Clays (Madejova and Komadel, 2001 and Chipera and Bish, 2001), the $\mathrm{SM}_{0.33}-1200$ sample can be considered as a good reference sample with classical band positions on the XRD pattern and on the infrared spectrum (Fig. 2 and Fig. 3e and Be). The impurities identified in the SWy-2 sample (quartz, feldspar, gypsum, mica, illite) represent $25 \%$ of the raw sample and always $5 \%$ after purification by $<2 \mu \mathrm{m}$ size fraction selection (Chipera and Bish, 2001). Moreover, in the structural formula of the SWy-2 sample, tetrahedral charge deficit and Fe octahedral cations were found ((1), Mermut and Faz Cano, 2001).

$$
\text { SWy-2: }\left(\mathrm{Na}_{0.14}, \mathrm{Ca}_{0.52}, \mathrm{~K}_{0.01}\right)\left(\mathrm{Si}_{7.89}, \mathrm{Al}_{0.11}\right)\left(\mathrm{Al}_{3.23}, \mathrm{Fe}_{0.42}, \mathrm{Mg}_{0.56}\right) \mathrm{O}_{20}(\mathrm{OH})_{4}
$$

The presence of iron in the structure of natural smectites can induce reactivities of these smectites such as the modification of the iron valence in reducing conditions (Stucki et al., 1984, Gates et al., 1993 and Gates et al., 1996), the easier deprotonation of iron smectites (Heller-Kallai, 2001) or the reaction between iron rich clays and metallic iron (Lantenois, 2003 and Lantenois et al., 2005). In some cases, the possibility to use a montmorillonite without iron content can have an important scientific interest. 
Other low charge montmorillonite samples were synthesized with a method developed by Reinholdt et al., 2001 and Reinholdt et al., 2005) in a slightly acidic and fluoride medium at low temperature and pressure $\left(200^{\circ} \mathrm{C}, P<5 \mathrm{MPa}\right)$. However, the ratio of synthesized crystallized phases was not given and the fluoride medium induces a fluorine partial integration in the montmorillonite structure.

The present study aimed to synthesize montmorillonites with different layer charge deficits to obtain a well-characterized reference smectites series. The experimental runs indicate that the pressure is an important factor. At $320^{\circ} \mathrm{C}$, a pressure fixed to $120 \mathrm{MPa}$ is sufficient to synthesize only octahedrally charged smectites. The pressure decrease or the increase of $\mathrm{Mg}$ content induced a tetrahedral charge deficit formation and the apparition of di-trioctahedral sample. To optimize the synthesized smectite amount, a run duration of 30 days is needed. In these conditions, only low charge deficit montmorillonite $(x=0.33)$ could be synthesized $\left(\mathrm{SM}_{0.33}-1200\right)$ with impurities and residual amorphous phases less than $3 \%$.

\section{Acknowledgments}

P. Baillif, O. Rouer (ISTO-Orléans) and M.-P. Faugère, A. Pineau (CRMD-Orléans) are thanked for their assistance.

\section{References}

Calvet and Prost, 1971 R. Calvet and R. Prost, Cation migration into empty octahedral sites and surface properties of clays, Clays and Clay Minerals 19 (1971), pp. 175-186.

Carrado et al., 1997 K.A. Carrado, P. Thiyagarajan and K. Song, A study of organo-hectorite clay crystallization, Clay Minerals 32 (1997), pp. 29-40.

Chipera and Bish, 2001 S.J. Chipera and D.L. Bish, Baseline studies of the clay minerals society source clays: powder X-ray diffraction analyses, Clays and Clay Minerals 49 (2001), pp. 398-409.

Decarreau et al., 1987 A. Decarreau, D. Bonnin, D. Badaut-Trauth, R. Couty and P. Kaiser, Synthesis and cristallogenesis of ferric smectite by evolution of $\mathrm{Si}-\mathrm{Fe}$ coprecipitates in oxidizing conditions, Clays and Clay Minerals 22 (1987), pp. 207-223.

Delevoye et al., 2003 L. Delevoye, J.-L. Robert and J. Grandjean, ${ }^{23}$ Na 2D 3QMAS NMR and ${ }^{29} \mathrm{Si},{ }^{27} \mathrm{Al}$ MAS NMR investigation of Laponite and synthetic saponites of variable interlayer charge, Clay Minerals 38 (2003), pp. 63-69.

Farmer, 1974 V.C. Farmer, The infrared spectra of minerals, Monograph 4, Mineralogical Society, London (1974) 539 pp.. 
Gaboriau, 1991 Gaboriau, H., 1991. Interstratifiés smectite-kaolinite de l'Eure. Thesis, Université d'Orléans, 274 pp.

Gates, 2004 W.P. Gates In: J.T. Kloprogge, Editor, Infrared spectroscopy and the chemistry of dioctahedral smectites in The Application of Vibrational Spectroscopy to Clay Minerals and Layered Double Hydroxides, CMS Workshop Lectures vol. 13, The Clay Minerals Society, Aurora, CO (2004), pp. 125-168.

Gates et al., 1993 W.P. Gates, H.T. Wilkinson and J.W. Stucki, Swelling properties of microbially reduced ferruginous smectite, Clays and Clay Minerals 41 (1993), pp. 360-364.

Gates et al., 1996 W.P. Gates, J.W. Stucki and R.J. Kirkpatrick, Structural properties of reduced Upton montmorillonite, Phys. Chem. Minerals 23 (1996), pp. 535-541.

Grauby et al., 1993 O. Grauby, S. Petit, A. Decarreau and A. Baronnet, The beidellitesaponite series: an experimental approach, European Journal of Mineralogy 5 (1993), pp. 623-635.

Greene-Kelly, 1953 R. Greene-Kelly, Identification of montmorillonoids, Journal of Soil Science 4 (1953), pp. 233-237.

Guggenheim and Koster van Groos, 2001 S. Guggenheim and A.F. Koster van Groos, Baseline studies of the clay minerals society source clays: thermal analysis, Clays and Clay Minerals 49 (2001), pp. 433-443.

Hamilton and Henderson, 1968 D.L. Hamilton and C.M.B. Henderson, The preparation of silicate compositions by a gelling method, Mineralogical Magazine 36 (1968), pp. 832-838.

Harward and Brindley, 1966 M.E. Harward and G.W. Brindley, Swelling properties of synthetic smectites in relation to lattice substitutions, Clays and Clay Minerals 13 (1966), pp. 209-222.

Heller-Kallai, 2001 L. Heller-Kallai, Protonation-deprotonation of dioctahedral smectites, Applied Clay Science 20 (2001), pp. 27-38

Hofmann and Klemen, 1950 V. Hofmann and R. Klemen, Verlust der Austauschfähigkeit von Lithiumionen aus Bentonit durch Erhitzung, Zeitschrift für Anorganische und Allgemeine Chemie 262 (1950), pp. 95-99.

Joussein et al., 2001 E. Joussein, S. Petit and A. Decarreau, Une nouvelle méthode de dosage des minéraux argileux en mélange par spectroscopie IR.C.R, Academic Science Earth and Planetary Sciences 332 (2001), pp. 83-89.

Kloprogge et al., 1990 J.T. Kloprogge, J.B.H. Jansen and J.W. Geus, Characterization of synthetic Na-beidellite, Clays and Clay Minerals 38 (1990), pp. 409-414.

Kloprogge et al., 1993 J.T. Kloprogge, A.M.J. van der Eerden, J.B.H. Jansen, J.W. Geus and R.D. Schuiling, Synthesis and paragenesis of Na-beidellite as function of temperature, water pressure and sodium activity, Clays and Clay Minerals 41 (1993), pp. 423-430. 
Kloprogge et al., 1999 J.T. Kloprogge, S. Komarneni and J.E. Amonette, Synthesis of smectite clay minerals: a critical review, Clays and Clay Minerals 47 (1999), pp. 529-554.

Lantenois, 2003 Lantenois, S., 2003. Réactivité fer métal/smectites en milieu hydraté à $80{ }^{\circ} \mathrm{C}$ . Ph.D. thesis, Université d'Orléans, 188 pp.

Lantenois et al., 2005 S. Lantenois, B. Lanson, F. Muller, A. Bauer, M. Jullien and A. Plançon, Experimental study of smectite interaction with metal Fe at low temperature: 1, Smectite destabilization. Clays and Clay Minerals 53 (2005), pp. 597-612

Levinson and Vian, 1966 A.A. Levinson and R.W. Vian, The hydrothermal synthesis of montmorillonite group minerals from kaolinite, quartz and various carbonates, American Mineralogist 51 (1966), pp. 495-498.

Levinson and Day, 1968 A.A. Levinson and J.J. Day, Low temperature hydrothermal synthesis of montmorillonite, ammonium-micas and ammonium-zeolites, Earth and Planetary Science Letters 5 (1968), pp. 52-54.

Lim and Jackson, 1986 C.H. Lim and M.L. Jackson, Expandable phyllosilicate reactions with lithium on heating, Clays and Clay minerals 34 (1986), p. 346-342.

Madejova, 2003 J. Madejova, FTIR techniques in clay mineral studies, Vibrational Spectroscopy 31 (2003), pp. 1-10.

Madejova and Komadel, $2001 \mathrm{~J}$. Madejova and P. Komadel, Baseline studies of the clay minerals society source clays: Infrared methods, Clays and Clay Minerals 49 (2001), pp. 410 432.

Madejova et al., 2000 J. Madejova, J. Bujdak, S. Petit and P. Komadel, Effects of chemical composition and temperature of heating on the infrared spectra of Li-saturated dioctahedral smectites. (I) Mid-infrared region, Clay Minerals 35 (2000), pp. 739-751.

Mermut and Faz Cano, 2001 A.R. Mermut and A. Faz Cano, Baseline studies of the clay minerals society source clays: chemical analyses of major elements, Clays and Clay Minerals 49 (2001), pp. 381-386.

Nakazawa et al., 1991 H. Nakazawa, H. Yamada, K. Yoshioka, M. Adachi and T. Fujita, Montmorillonite crystallization from glass, Clay Science 8 (1991), pp. 59-68.

Pelletier et al., 1999 M. Pelletier, L.J. Michot, O. Barrès, B. Humbert, S. Petit and J.L. Robert, Influence of $\mathrm{KBr}$ conditioning on the infrared hydroxyl-stretching region of saponites, Clay Minerals 34 (1999), pp. 439-445.

Qi et al., 1996 Y. Qi, M. Al-Mukhtar, J.-F. Alcoverm and F. Bergaya, Coupling analysis of macroscopic and microscopic behaviour in highly consolidated Na-laponite clays, Applied Clay Science 11 (1996), pp. 185-197.

Reinholdt et al., 2001 M. Reinholdt, J. Miehé-Brendlé, L. Delmotte, M.-H. Tuilier, R. Le Dred, R. Cortès and A.-M. Flank, Fluorine route synthesis of montmorillonites containing Mg 
or Zn and characterization by XRD, Thermal Analysis, MAS NMR and EXAFS spectroscopy, European Journal of Inorganic Chemistry (2001), pp. 2831-2841.

Reinholdt et al., 2005 M. Reinholdt, J. Miehé-Brendlé, L. Delmotte, R. Le Dred and M.-H. Tuilier, Synthesis and characterization of montmorillonite-type phyllosilicates in a fluoride medium, Clay Minerals 40 (2005), pp. 177-189.

Roux and Volfinger, $1996 \mathrm{~J}$. Roux and M. Volfinger, Mesures précises à l'aide d'un détecteur courbe, Journal de Physique IV (1996), pp. 127-134.

Roy and Sand, 1956 R. Roy and L.B. Sand, A note on some properties of synthetic montmorillonites, American Mineralogist 41 (1956), pp. 505-509.

Sand et al., 1953 L.B. Sand, R. Roy and E.F. Osborn, Stability relations of some minerals in the system $\mathrm{Na}_{2} \mathrm{O}-\mathrm{Al}_{2} \mathrm{O}_{3}-\mathrm{SiO}_{2}-\mathrm{H}_{2} \mathrm{O}$, Bulletin of the Geological Society of America 64 (1953), pp. 1469-1470.

Sand et al., 1957 L.B. Sand, R. Roy and E.F. Osborn, Stability relations of some minerals in the $\mathrm{Na} 2 \mathrm{O}-\mathrm{Al}_{2} \mathrm{O}_{3}-\mathrm{SiO}_{2}-\mathrm{H}_{2} \mathrm{O}$ system, Economic Geology 52 (1957), pp. 169-179.

Sanz and Serratosa, 1984 J. Sanz and J.M. Serratosa, 29Si and 27AL High-Resolution MASNMR Spectra of Phyllosilicates, Journal of American Chemical Society 106 (1984), pp. $4790-4793$.

Stucki et al., 1984 J.W. Stucki, D.C. Golden and C.B. Roth, Effects of reduction and reoxidation of structural $\mathrm{Fe}$ on the surface charge and dissolution of dioctahedral smectites, Clays and Clay Minerals 32 (1984), pp. 350-356.

Suquet et al., 1977 H. Suquet, J.T. Iiyama, H. Kodama and H. Pezerat, Synthesis and swelling properties of saponites with increasing layer charge, Clays and Clay Minerals 25 (1977), pp. $231-242$.

Suquet et al., 1982 H. Suquet, R. Prost and H. Pezerat, Etude par spectroscopie infrarouge et diffraction $\mathrm{X}$ des interactions eau-cation-feuillet dans les phases à 14.6, 12.2 et $10.1 \AA$ d'une saponite-Li de synthese, Clay Minerals 17 (1982), pp. 231-241.

Yamada et al., 1991 H. Yamada, H. Nakazawa, K. Yoshioka and T. Fujita, Smectites in the montmorillonite-beidellite series, Clay Minerals 26 (1991), pp. 359-369.

Yamada et al., 1994a H. Yamada, H. Nakazawa and H. Hashizume, Formation of smectite crystals at high pressures and temperatures, Clays and Clay Minerals 42 (1994), pp. 674-678.

Yamada et al., 1994b H. Yamada, H. Nakazawa, H. Hashizume, S. Shimomura and T.

Watanabe, Hydration behaviour of Na-smectite crystals synthesized at high pressure and high temperature, Clays and Clay Minerals 42 (1994), pp. 77-80. 


\section{Figures}

A

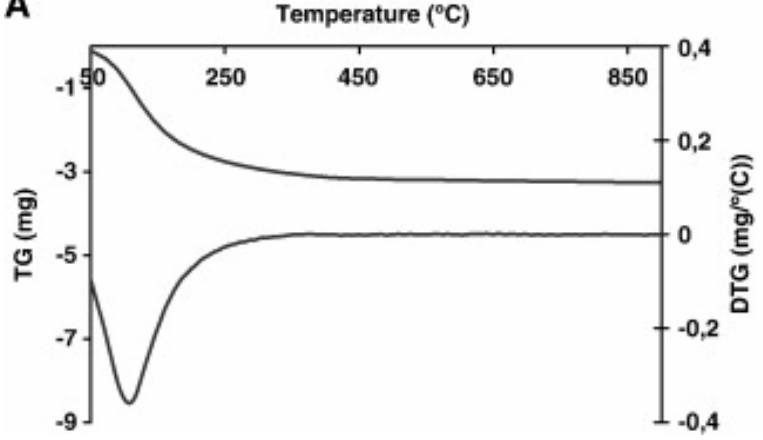

B

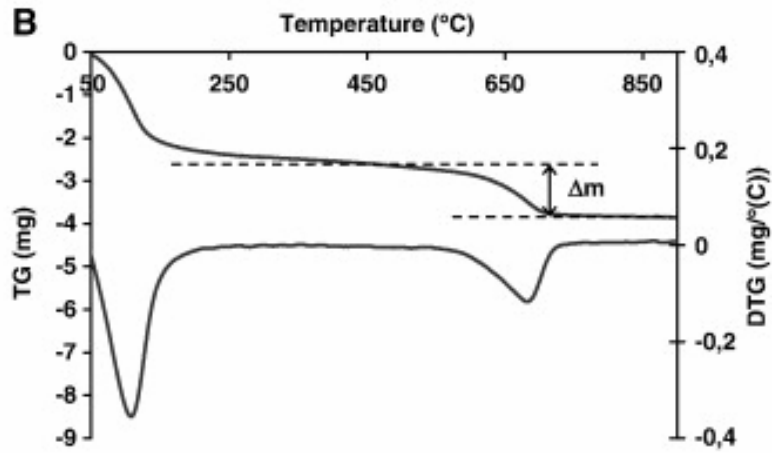

Fig. 1. TG and DTG curve of $\mathrm{GM}_{0.33}$ starting gel phase (A) and $\mathrm{SM}_{0.33}-1200$ sample (B). $\Delta \mathrm{m}$ corresponds to the mass loss of structural $\mathrm{OH}$ in smectite clay.

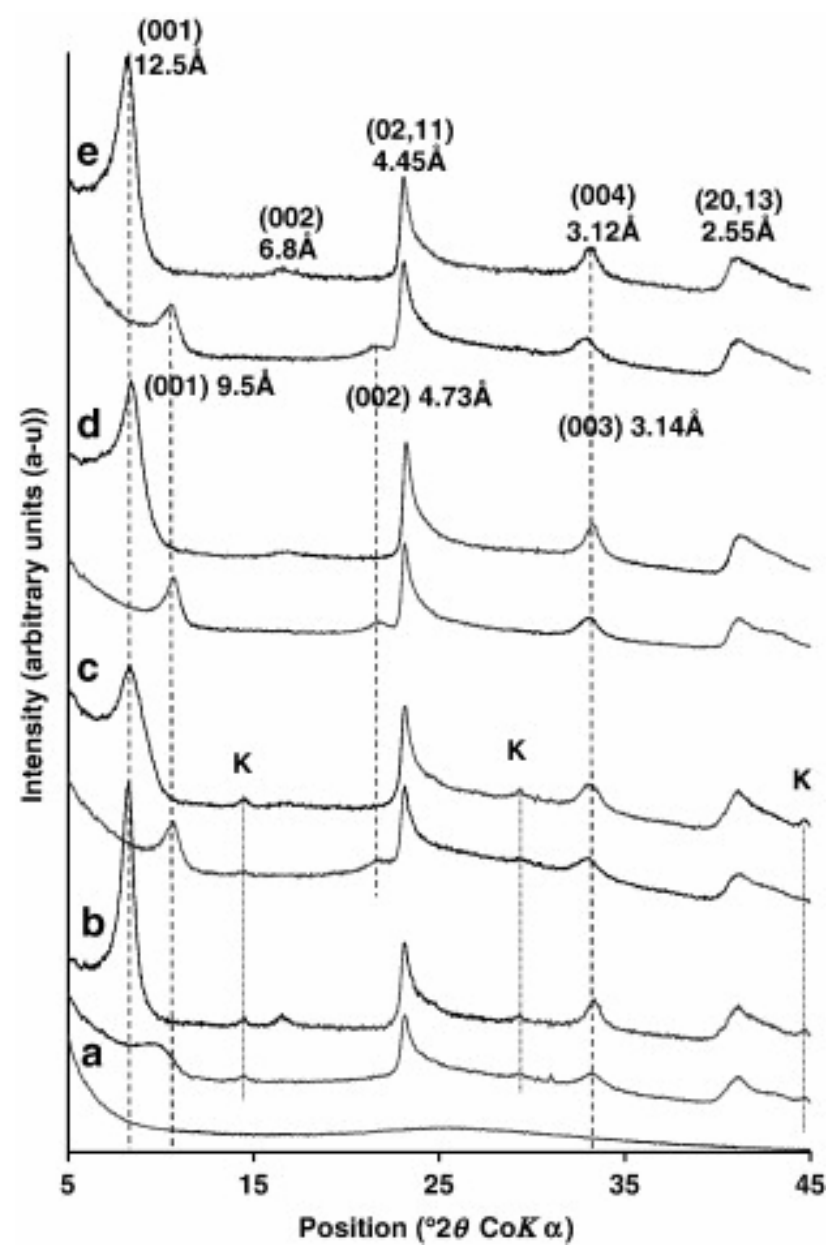

Fig. 2. XRD patterns of $\mathrm{GM}_{0.33}$ starting gel phase (a) and synthetic $\mathrm{SM}_{0.33}$ sample in natural state and after GK test (upper and lower patterns respectively) at various synthesis pressures. (b) $\mathrm{SM}_{0.33}-200$, (c) $\mathrm{SM}_{0.33}-800$, (d) $\mathrm{SM}_{0.33}-1200$ and (e) $\mathrm{SM}_{0.33}-2000$. The (00 $\ell$ ) reflections (dashed lines) and the $(02,11)$ and the $(20,13)$ bands of smectites are labelled. $\mathrm{K}$ indicates the presence of formed kaolinite phase in some samples (dotted lines). 

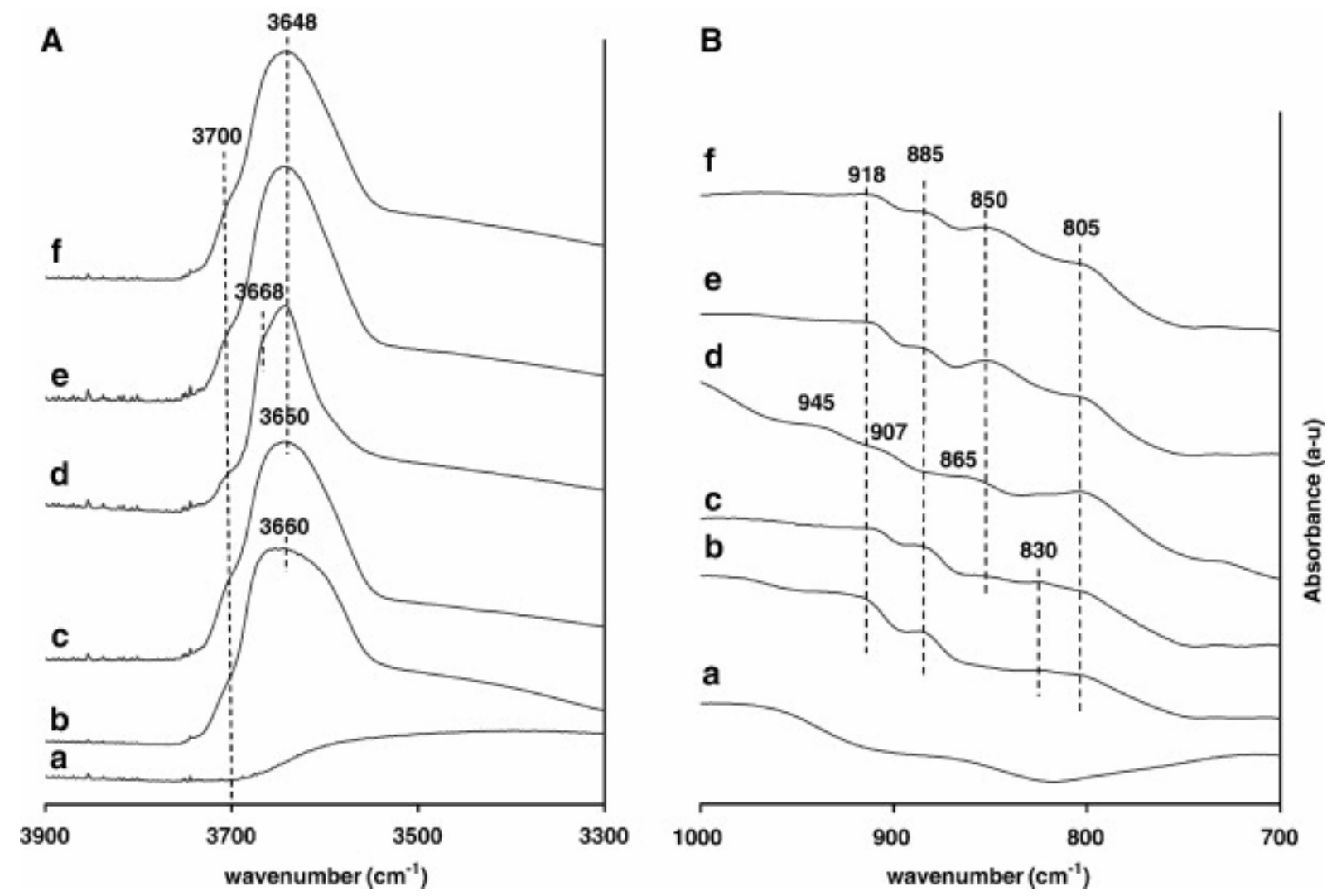

Fig. 3. Infrared spectra of synthetic $\mathrm{SM}_{0.33}$ sample at various synthesis pressures in the $\mathrm{OH}$ stretching zone (A) and in the $\mathrm{OH}$ bending zone (B). (a) Amorphous $\mathrm{GM}_{0.33}$ phase, (b) $\mathrm{SM}_{0.33^{-}}$ 200, (c) $\mathrm{SM}_{0.33}-800$, (d) $\mathrm{SM}_{0.33}-1200$ after GK test, (e) $\mathrm{SM}_{0.33}-1200$ and (f) $\mathrm{SM}_{0.33}-2000$. Smectite $\mathrm{OH}$ vibration bands are labelled (dashed lines).

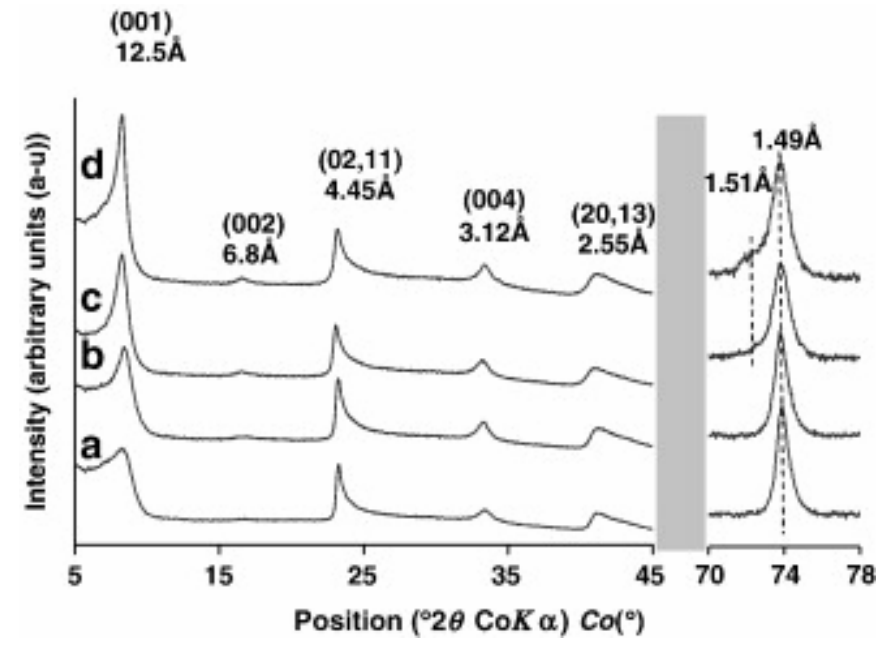

Fig. 4. XRD patterns of synthetic montmorillonite with various layer charges. (a) $\mathrm{SM}_{0.25^{-}}$

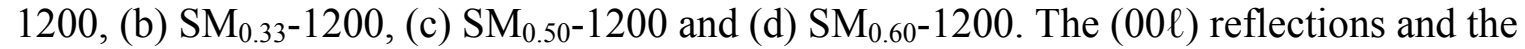
$(02,11),(20,13)$ and $(06,33$; dashed lines $)$ bands of smectites are labelled. Scale factor $(x 4)$ over the $70-78^{\circ} 2 \theta \mathrm{CoK} \alpha$ range. 
A

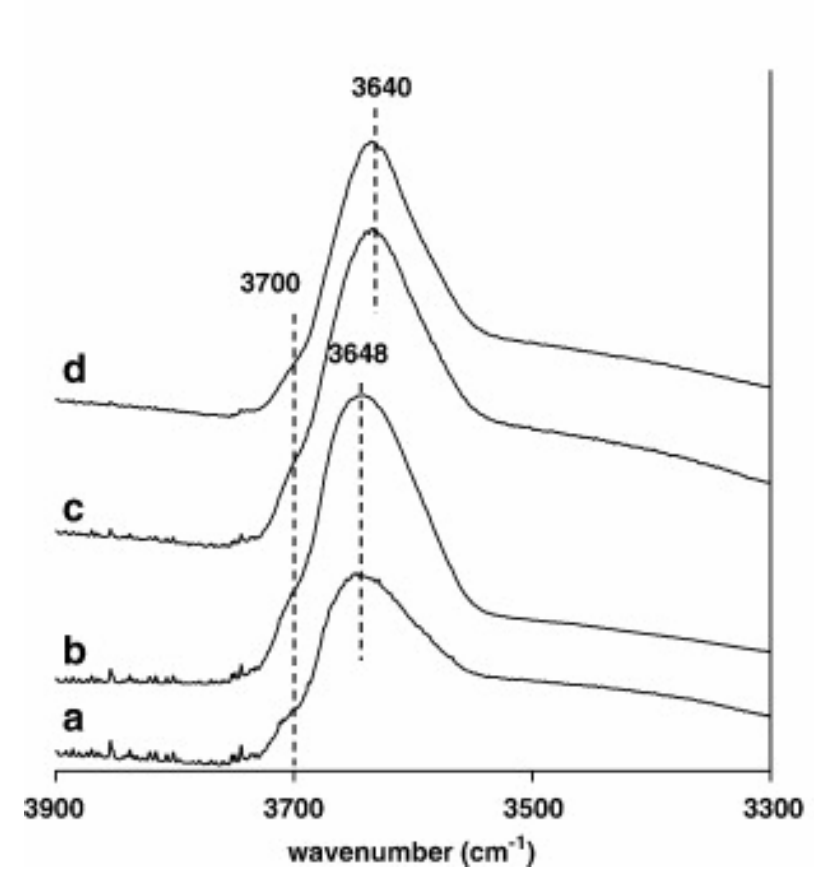

B

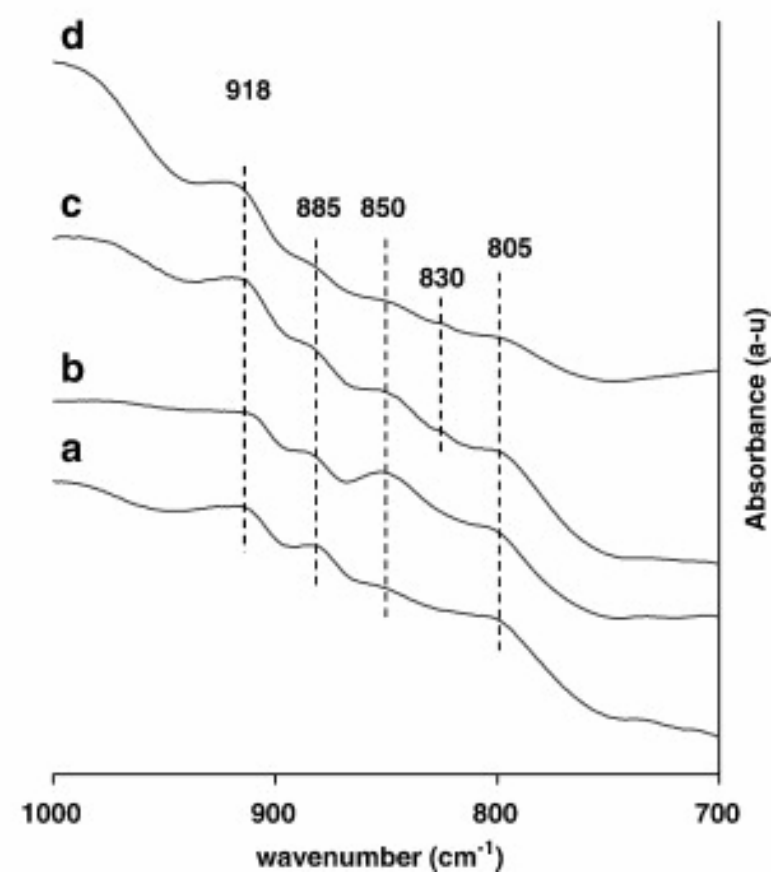

Fig. 5. Infrared spectra of synthetic montmorillonites with various layer charges in the $\mathrm{OH}$ stretching zone (A) and in the $\mathrm{OH}$ bending zone (B). (a) $\mathrm{SM}_{0.25}-1200$, (b) $\mathrm{SM}_{0.33}-1200$, (c) $\mathrm{SM}_{0.50}-1200$ and (d) $\mathrm{SM}_{0.60}-1200$. Smectite $\mathrm{OH}$ vibration bands are labelled (dashed lines).

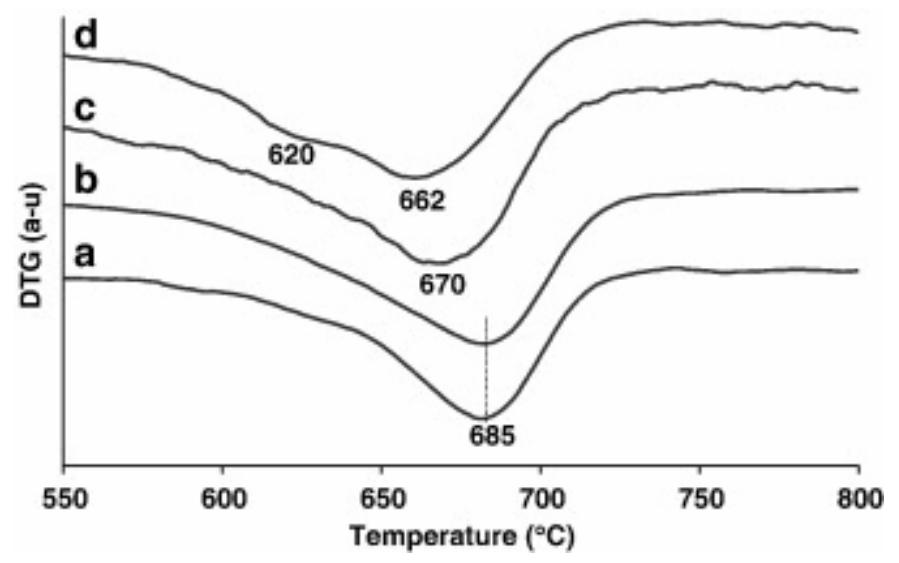

Fig. 6. DTG curve of synthetic montmorillonites with various layer charges in the $550-800{ }^{\circ} \mathrm{C}$ temperature range. (a) $\mathrm{SM}_{0.25}-1200$, (b) $\mathrm{SM}_{0.33}-1200$, (c) $\mathrm{SM}_{0.50^{-}} 1200$ and (d) $\mathrm{SM}_{0.60}-1200$. 
A

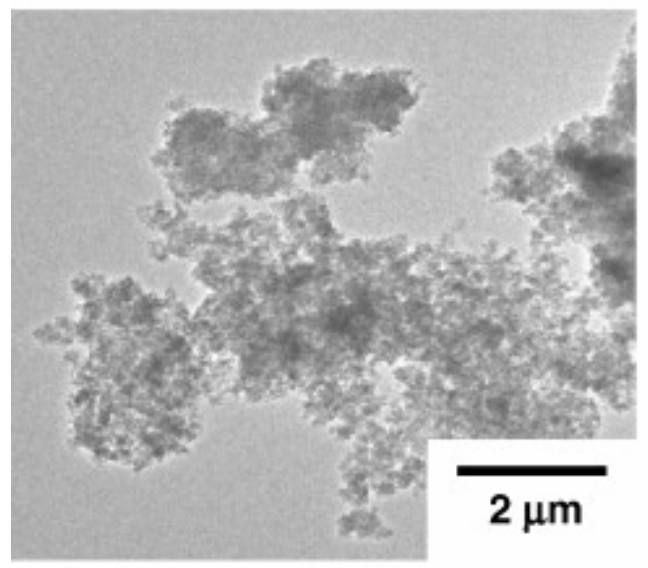

C

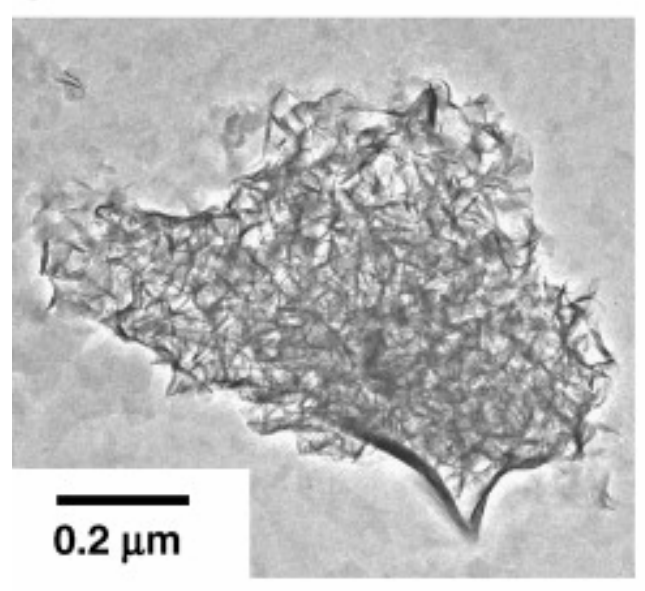

B

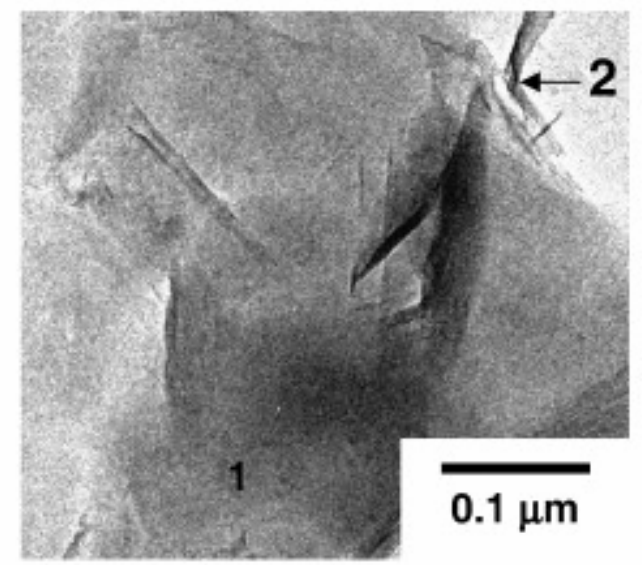

D

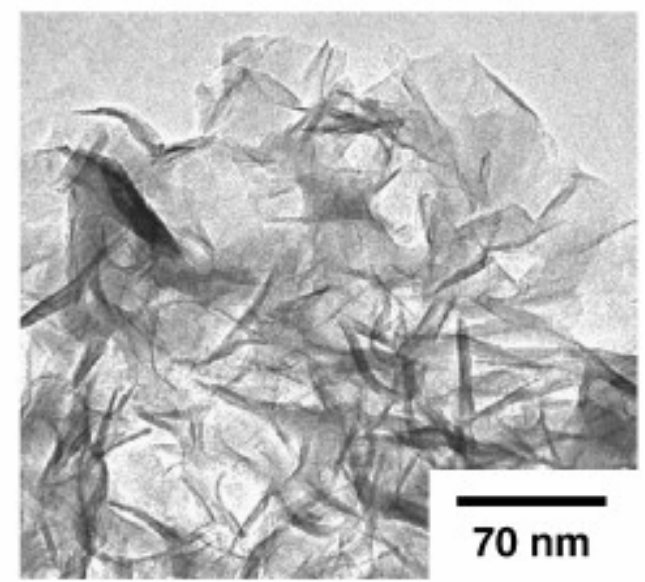

Fig. 7. TEM images of $\mathrm{SM}_{0.33}$ samples. (A) Amorphous phase $\mathrm{GM}_{0.33}$ before hydrothermal synthesis. (B) Residual amorphous phase (1) and neoformed smectite particles (2) in $\mathrm{SM}_{0.33^{-}}$ 1200 sample after 15 days run time. (C) and (D) smectite particles in $\mathrm{SM}_{0.33}-1200$ sample after 30 days run duration and in the $<2 \mu \mathrm{m}$ size fine fraction respectively.

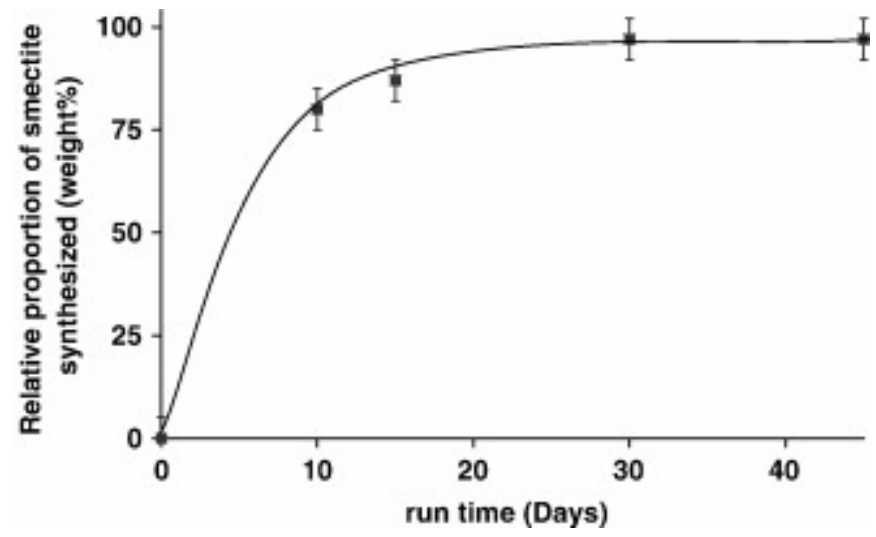

Fig. 8. Relative proportion of formed smectite phase (wt.\%) after hydrothermal synthesis in $\mathrm{SM}_{0.33}$ sample at 1200 bars as a function of run duration. Relative proportion of formed smectite phase was estimated using TGA measurements. 


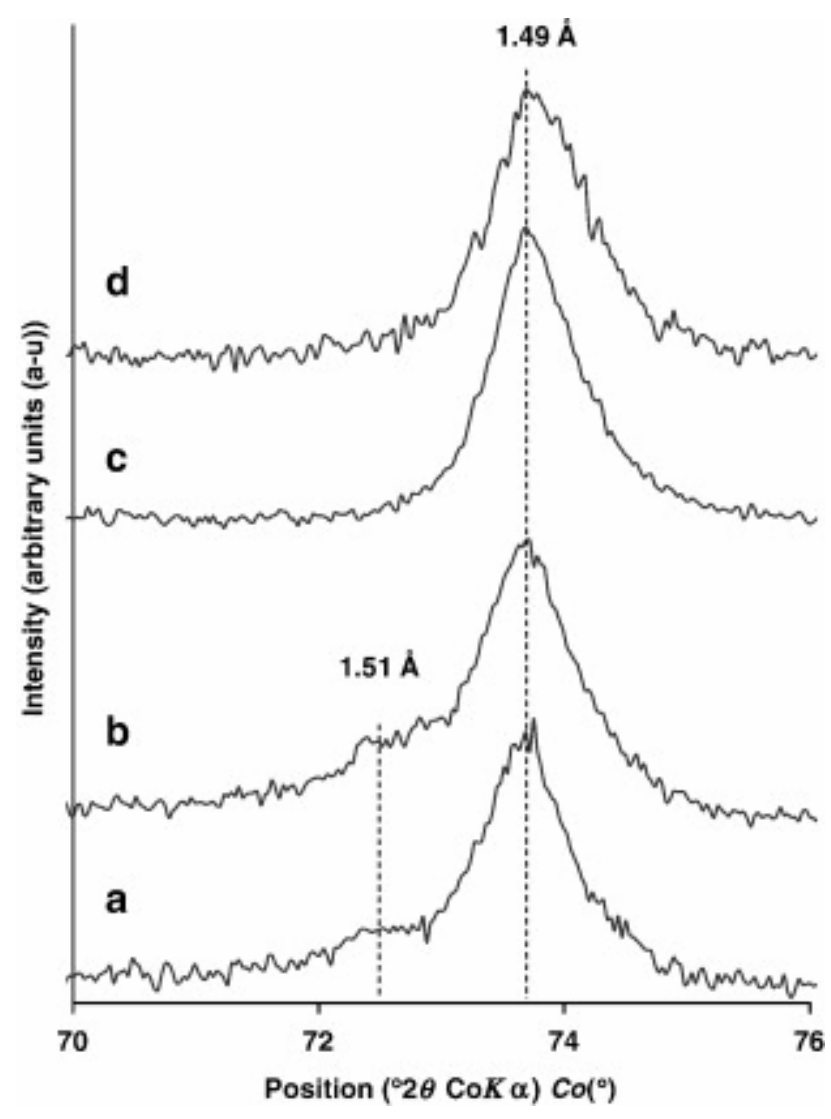

Fig. 9. XRD patterns of synthetic $\mathrm{SM}_{0.33}$ sample in natural state at various synthesis pressures in the 70-76 $2 \theta$ CoK $\alpha$ range. (a) $\mathrm{SM}_{0.33}-200$, (b) $\mathrm{SM}_{0.33^{-}} 800$, (c) $\mathrm{SM}_{0.33^{-}} 1200$ and (d) $\mathrm{SM}_{0.33^{-}}$ 2000. The $(06,33)$ band is labelled (dashed lines). 


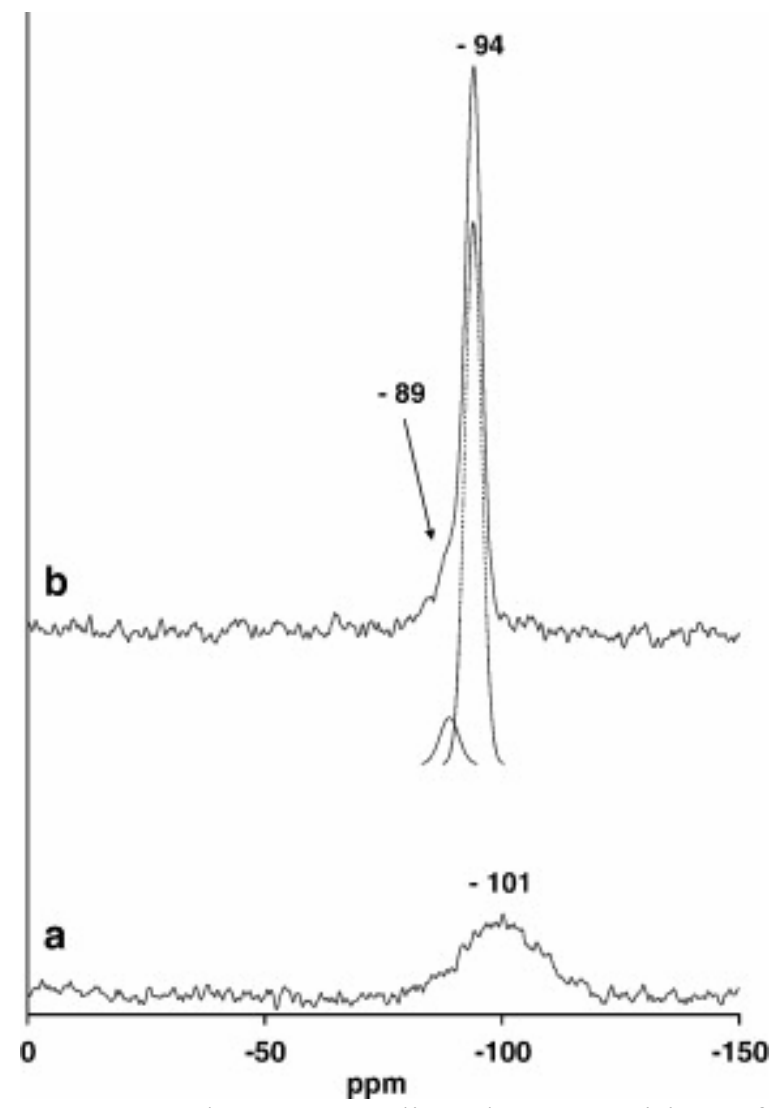

Fig. 10. ${ }^{29}$ Si MAS NMR spectra and corresponding decomposition of synthetic $\mathrm{SM}_{0.33}-1200$ sample (b) and starting amorphous phase GM0.33 (a). 


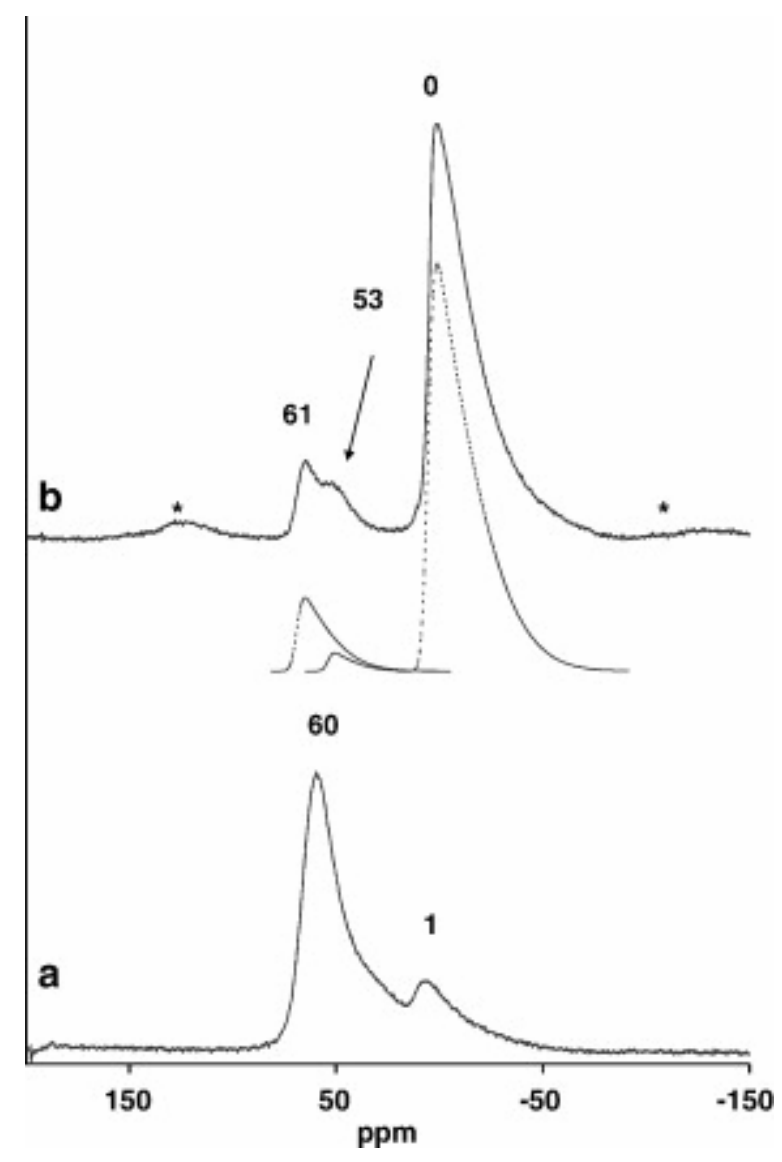

Fig. 11. ${ }^{27} \mathrm{Al}$ MAS NMR spectra and corresponding decomposition of synthetic $\mathrm{SM}_{0.33}-1200$ sample (b) and starting amorphous phase GM0.33 (a). corresponds to spinning sidebands. 
Tables

Table 1. : Chemical composition (in oxide weights normalised to 100\%) of starting gel phases measured by ICP-AES

\begin{tabular}{|l|l|l|l|l|}
\hline Sample & $\mathbf{G M}_{\mathbf{0 . 2 5}}$ & $\mathbf{G M}_{\mathbf{0 . 3 3}}$ & $\mathbf{G M}_{\mathbf{0 . 5 0}}$ & $\mathbf{G M}_{\mathbf{0 . 6 0}}$ \\
\hline $\boldsymbol{x}$ value & $\mathbf{0 . 2 5}$ & $\mathbf{0 . 3 3}$ & $\mathbf{0 . 5 0}$ & $\mathbf{0 . 6 0}$ \\
\hline $\mathrm{SiO}_{2}$ & 68.6 & 68.9 & 67.4 & 67.6 \\
\hline $\mathrm{Al}_{2} \mathrm{O}_{3}$ & 26.4 & 24.5 & 22.6 & 20.8 \\
\hline $\mathrm{Fe}_{2} \mathrm{O}_{3}$ & 0.0 & 0.0 & 0.0 & 0.0 \\
\hline $\mathrm{MgO}$ & 3.0 & 4.0 & 6.0 & 6.9 \\
\hline $\mathrm{Na}_{2} \mathrm{O}$ & 2.0 & 2.6 & 4.0 & 4.7 \\
\hline
\end{tabular}

Table 2. : Experimental conditions and reaction products of all experiments

\begin{tabular}{|c|c|c|c|c|c|}
\hline Sample name & Starting gel phase & $T\left({ }^{\circ} \mathrm{C}\right)$ & $\mathbf{M P a}$ & Time (days) & Product \\
\hline $\mathrm{SM}_{0.33}-200$ & $\mathrm{GM}_{0.33}$ & 320 & 20 & 15 & Beid, Sapo, Kaol \\
\hline $\mathrm{SM}_{0.33}-800$ & $\mathrm{GM}_{0.33}$ & 320 & 80 & 15 & Mont $\quad$, Kaol \\
\hline $\mathrm{SM}_{0.33}-1200$ & $\mathrm{GM}_{0.33}$ & 320 & 120 & 15 & Mont \\
\hline $\mathrm{SM}_{0.33}-2000$ & $\mathrm{GM}_{0.33}$ & 320 & 200 & 15 & Mont \\
\hline $\mathrm{SM}_{0.25}-1200$ & $\mathrm{GM}_{0.25}$ & 320 & 120 & 15 & Mont \\
\hline $\mathrm{SM}_{0.50}-1200$ & $\mathrm{GM}_{0.50}$ & 320 & 120 & 15 & Mont \\
\hline $\mathrm{SM}_{0.60}-1200$ & $\mathrm{GM}_{0.60}$ & 320 & 120 & 15 & Mont \\
\hline $\mathrm{SM}_{0.50}-2000$ & $\mathrm{GM}_{0.50}$ & 320 & 200 & 15 & Mont \\
\hline $\mathrm{SM}_{0.33}-1200 \mathrm{a}$ & $\mathrm{GM}_{0.33}$ & 320 & 120 & 5 & Mont \\
\hline $\mathrm{SM}_{0.33}-1200 \mathrm{~b}$ & $\mathrm{GM}_{0.33}$ & 320 & 120 & 10 & Mont \\
\hline $\mathrm{SM}_{0.33}-1200 \mathrm{c}$ & $\mathrm{GM}_{0.33}$ & 320 & 120 & 30 & Mont \\
\hline $\mathrm{SM}_{0.33}-1200 \mathrm{~d}$ & $\mathrm{GM}_{0.33}$ & 320 & 120 & 45 & Mont \\
\hline
\end{tabular}


Note: ${ }^{*}$ crystallised phases identified by XRD. Beid, Sap, Mont and Kaol correspond to beidellite, saponite, montmorillonite and kaolinite clay phases respectively. Presence of tetrahedral charge deficits and trioctahedral domains (identified by chemical analysis).

Table 3. : Relevant parameters of the solid-state NMR investigation for ${ }^{27} \mathrm{Al}$ and ${ }^{29} \mathrm{Si}$ nuclei

\begin{tabular}{|l|l|l|l|l|l|l|}
\hline Nuclei & $\boldsymbol{v}(\mathbf{M H z})$ & Reference & T pulse ( $\boldsymbol{\mu s})$ & $\boldsymbol{\theta}\left({ }^{\circ}\right)$ & $\boldsymbol{t}_{\text {ree. }}(\mathbf{s})$ & Spinning rate $(\mathrm{KHz})$ \\
\hline${ }^{29} \mathrm{Si}$ & 59.62 & $\mathrm{TMS}$ & 2.25 & 90 & 10 & 5 \\
\hline${ }^{27} \mathrm{Al}$ & 78.20 & $\mathrm{Al}\left(\mathrm{NO}_{3}\right)_{3}$ aq. & 4.0 & 30 & 1 & 10 \\
\hline
\end{tabular}

$v$ - operating frequency, T pulse - pulse length, $\theta$ - pulse angle, $t_{\text {rec. }}$ - recycle time, TMS — tetramethylsilane. 
Table 4. : Chemical composition of the synthetic smectites (structural formulae calculated per $\left.\mathrm{O}_{10}(\mathrm{OH})_{2}\right)$, cation exchange capacity (meq/100 g of calcined clay) and synthesized smectite weight ratio

\begin{tabular}{|c|c|c|c|c|c|c|c|c|c|c|c|}
\hline & $\mathbf{G M}_{0.33}$ & $\begin{array}{l}\mathrm{SM}_{0.33^{-}} \\
200\end{array}$ & $\begin{array}{l}\mathrm{SM}_{0.33^{-}} \\
\mathbf{8 0 0}\end{array}$ & $\begin{array}{l}\mathrm{SM}_{0.33^{-}} \\
1200\end{array}$ & $\begin{array}{l}\mathrm{SM}_{0.33^{-}} \\
2000\end{array}$ & $\mathbf{G M}_{0.25}$ & $\begin{array}{l}\mathrm{SM}_{0.25^{-}} \\
1200\end{array}$ & $\mathbf{G M}_{0.50}$ & $\begin{array}{l}\mathrm{SM}_{0.50^{-}} \\
1200\end{array}$ & $\mathbf{G M}_{0.60}$ & $\begin{array}{l}\mathrm{SM}_{0.60^{-}} \\
1200\end{array}$ \\
\hline \multicolumn{12}{|l|}{ Tetrahedral } \\
\hline $\mathrm{Si}$ & 4.00 & 3.67 & 3.84 & 3.97 & 3.97 & 3.95 & 3.89 & 3.99 & 3.89 & 3.99 & 3.85 \\
\hline $\mathrm{Al}$ & 0.00 & 0.33 & 0.16 & 0.03 & 0.03 & 0.05 & 0.11 & 0.01 & 0.11 & 0.01 & 0.15 \\
\hline Charge deficit & 0.00 & -0.33 & -0.16 & -0.03 & -0.03 & -0.05 & -0.11 & -0.01 & -0.11 & -0.01 & -0.15 \\
\hline \multicolumn{12}{|l|}{ Octahedral } \\
\hline $\mathrm{Al}$ & 1.67 & 1.67 & 1.69 & 1.66 & 1.67 & 1.74 & 1.78 & 1.52 & 1.51 & 1.42 & 1.40 \\
\hline $\mathrm{Mg}$ & 0.35 & 0.48 & 0.38 & 0.36 & 0.35 & 0.26 & 0.26 & 0.51 & 0.59 & 0.60 & 0.72 \\
\hline occupancy & 2.02 & 2.15 & 2.07 & 2.02 & 2.02 & 2.00 & 2.04 & 2.03 & 2.10 & 2.02 & 2.12 \\
\hline Charge deficit & -0.29 & -0.03 & -0.17 & -0.30 & -0.29 & -0.26 & -0.14 & -0.42 & -0.29 & -0.54 & -0.36 \\
\hline \multicolumn{12}{|l|}{ Interlayer } \\
\hline $\mathrm{Na}$ & 0.29 & 0.36 & 0.33 & 0.34 & 0.32 & 0.29 & 0.24 & 0.45 & 0.40 & 0.55 & 0.51 \\
\hline Charge & +0.29 & +0.36 & +0.33 & +0.34 & +0.32 & +0.29 & +0.24 & +0.45 & +0.40 & +0.55 & +0.51 \\
\hline CEC & & 111 & 104 & 109 & 112 & & 91 & & 98 & & 103 \\
\hline
\end{tabular}




\begin{tabular}{|c|c|c|c|c|c|c|c|c|c|c|c|}
\hline & $\mathbf{G M}_{0.33}$ & $\begin{array}{l}\mathbf{S M}_{0.33^{-}} \\
\mathbf{2 0 0}\end{array}$ & $\begin{array}{l}\mathbf{S M}_{0.33^{-}} \\
\mathbf{8 0 0}\end{array}$ & $\begin{array}{l}\mathbf{S M}_{0.33^{-}} \\
1200\end{array}$ & $\begin{array}{l}\mathbf{S M}_{0.33^{-}} \\
\mathbf{2 0 0 0}\end{array}$ & $\mathbf{G M}_{0.25}$ & $\begin{array}{l}\mathbf{S M}_{0.25^{-}} \\
1200\end{array}$ & $\mathbf{G M}_{0.50}$ & $\begin{array}{l}\mathrm{SM}_{0.50^{-}} \\
1200\end{array}$ & $\mathbf{G M}_{0.60}$ & $\begin{array}{l}\mathbf{S M}_{0.60^{-}} \\
1200\end{array}$ \\
\hline $\mathrm{CEC}(\mathrm{GK})^{1}$ & & 81 & 42 & 8 & 10 & & 22 & & 25 & & 39 \\
\hline
\end{tabular}

Notes: ${ }^{*}$ theoretical formula calculated using chemical analysis in Table 1. ${ }^{1} \mathrm{CEC}$ measurement after Green-Kelly test. ${ }^{2}$ Determinated using OH mass deficit in TGA measurement. 
Table 5. : Chemical shifts, surface area and tetrahedral $\mathrm{Al} /(\mathrm{Al}+\mathrm{Si})$ ratio of $\mathrm{SM}_{0.33}-1200$ sample deduced from ${ }^{29} \mathrm{Si}$ and ${ }^{27} \mathrm{Al}$ and MAS NMR spectra

\begin{tabular}{|l|l|l|l|l|}
\hline & Chemical shift (ppm) & Attribution $^{\mathbf{1}}$ & Surface area (\%) $^{\circ}$ & $\mathbf{A l}(\mathbf{I V}) /(\mathrm{Si}+\mathbf{A l}(\mathbf{I V}))$ ratio \\
\hline${ }^{29} \mathrm{Si} \mathrm{MAS} \mathrm{NMR}$ & -94 & $\mathrm{Si}(0 \mathrm{Al})$ & 95 & $1-2 \%^{2}$ \\
\hline & -89 & $\mathrm{Si}(1 \mathrm{Al})$ & 5 & \\
\hline & -84 & $\mathrm{Si}(2 \mathrm{Al})$ & 0 & \\
\hline${ }^{27} \mathrm{Al}$ MAS NMR & 0 & $\mathrm{Al}(\mathrm{VI})$ & 85 & $1 \%^{3}$ \\
\hline & 53 & $\mathrm{Al}(\mathrm{IV})$ & 2.0 & \\
\hline & 61 & $\mathrm{Al}(\mathrm{IV})$ & 13.0 & \\
\hline
\end{tabular}

Notes: ${ }^{1}$ Sanz and Serratosa (1984), Reinholdt et al., 2001 and Reinholdt et al., 2005. 